\title{
ArbVias - MÉTODO DE AVALIAÇÃO DA ARBORIZAÇÃO NO SISTEMA VIÁRIO URBANO
}

\author{
ArbVias - EVALUATION METHOD OF FORESTATION IN THE URBAN STREETS
}

Roberto Vignola Junior*

\section{RESUMO}

O presente trabalho tem como foco introduzir um processo de leitura e interpretação da distribuição da arborização no sistema viário público urbano. Para tanto foi criado um método, com a utilização de software Sistema de Informação Geográfica (GIS), denominado ArbVias, que possibilita medições de frequência de indivíduos (árvores) e a sua classificação por continuidade de cobertura de suas copas. Para a apresentação do experimento partiu-se do mapeamento e incorporação de atributos em banco de dados georreferenciados para o sistema viário público da cidade de São Paulo, utilizando como estudo de caso uma região administrativa da capital paulistana, finalizando resultados através de efeitos de interpretação por cores, segundo legenda própria, que permite rápida visualização da situação da arborização no sistema viário.

Palavras-chave: Método. Arborização. Sistema viário. Mapeamento. Avaliação.

\section{ABSTRACT}

This paper introduces an evaluation process of trees distribution in urban streets. The method, named ArbVias, based upon Geographic Information System (GIS) soffware, allows measurements of frequency of individuals (trees) and their classification for continued canopy coverage over the street space via color styling with proper classification legend. As a result the method ArbVias leads to a quick visualization of the forestation state in the urban streets.

Keywords: Method. Forestation. Road system. Mapping. Evaluation.

\section{A IMPORTÂNCIA DA ARBORIZAÇÃO}

No Brasil, a partir da segunda metade do século XIX, começa a popularizar-se o entendimento de que a existência de arborização de ruas nas cidades é de vital importância na qualificação dos espaços livres urbanos'. Em 1896, o então intendente municipal de polícia e "hygiene" de São Paulo, dr. José Roberto Leite Penteado, através do "Acto" n 7, de 28 de março de 1896, oficializa regras para a arborização de ruas - com a participação de munícipes - como pretexto para o "embelezamento da cidade". No entanto, tornar viável a arborização nesses espaços livres da cidade exige

Segundo Andrade (2004, p. 107), como sinônimo de higienização, salubridade e estética.

Graduado em Engenharia Civil pela Universidade Presbiteriana Mackenzie. Mestre em Arquitetura e Urbanismo pela Faculdade de Arquitetura e Urbanismo da Universidade de São Paulo (FAUUSP). Pesquisador do Laboratório Quadros do Paisagismo no Brasil (Quapá) da FAUUSP. Rua do Lago, 876, 05508-080, Cidade Universitária, São Paulo, SP, Brasil.

roberto.vignola@usp.br 
cuidadoso trabalho para que essa associação também possibilite à sociedade múltiplas maneiras de vivenciá-los de forma segura, confortável e saudável.

Apesar de ser consenso a necessidade de arborização, a sua implementação não é fácil dentro do meio urbano de cidades contemporâneas como São Paulo, pela falta de espaço adequado para sua implantação.

Nas cidades brasileiras, historicamente, as calçadas têm dimensões reduzidas e apresentam grande descontinuidade, confirmando, com raras exceções, que seu desenho, tratamento e manutenção não têm sido assumidos devidamente pelo poder público, ficando a cargo dos moradores.

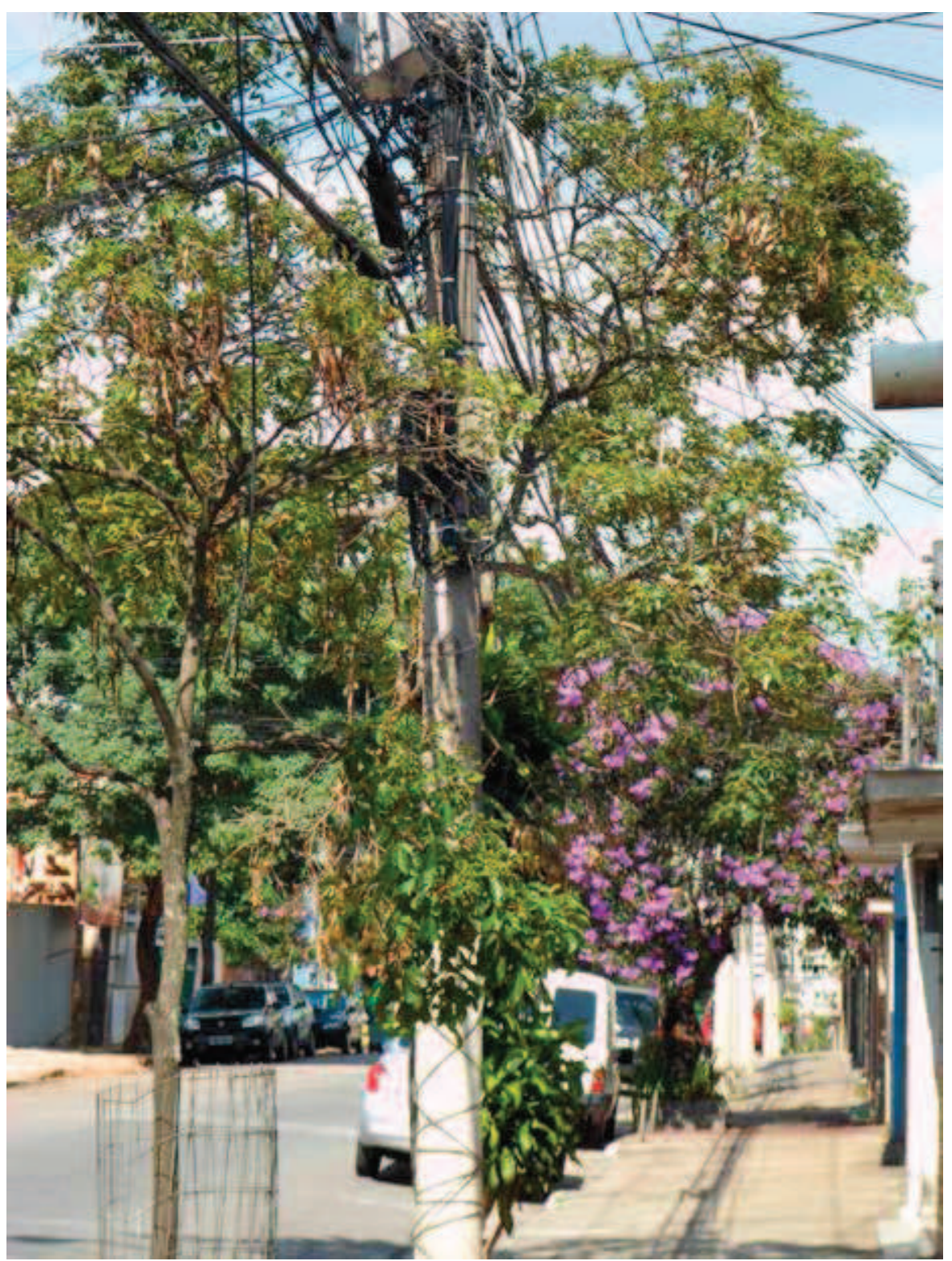

Figura la Conflitos aéreos e subterrâneos com a arborização. Rua Ibituruna, Parque Imperial, São Paulo (SP).

Foto: Roberto Vignola Junior - 2014 


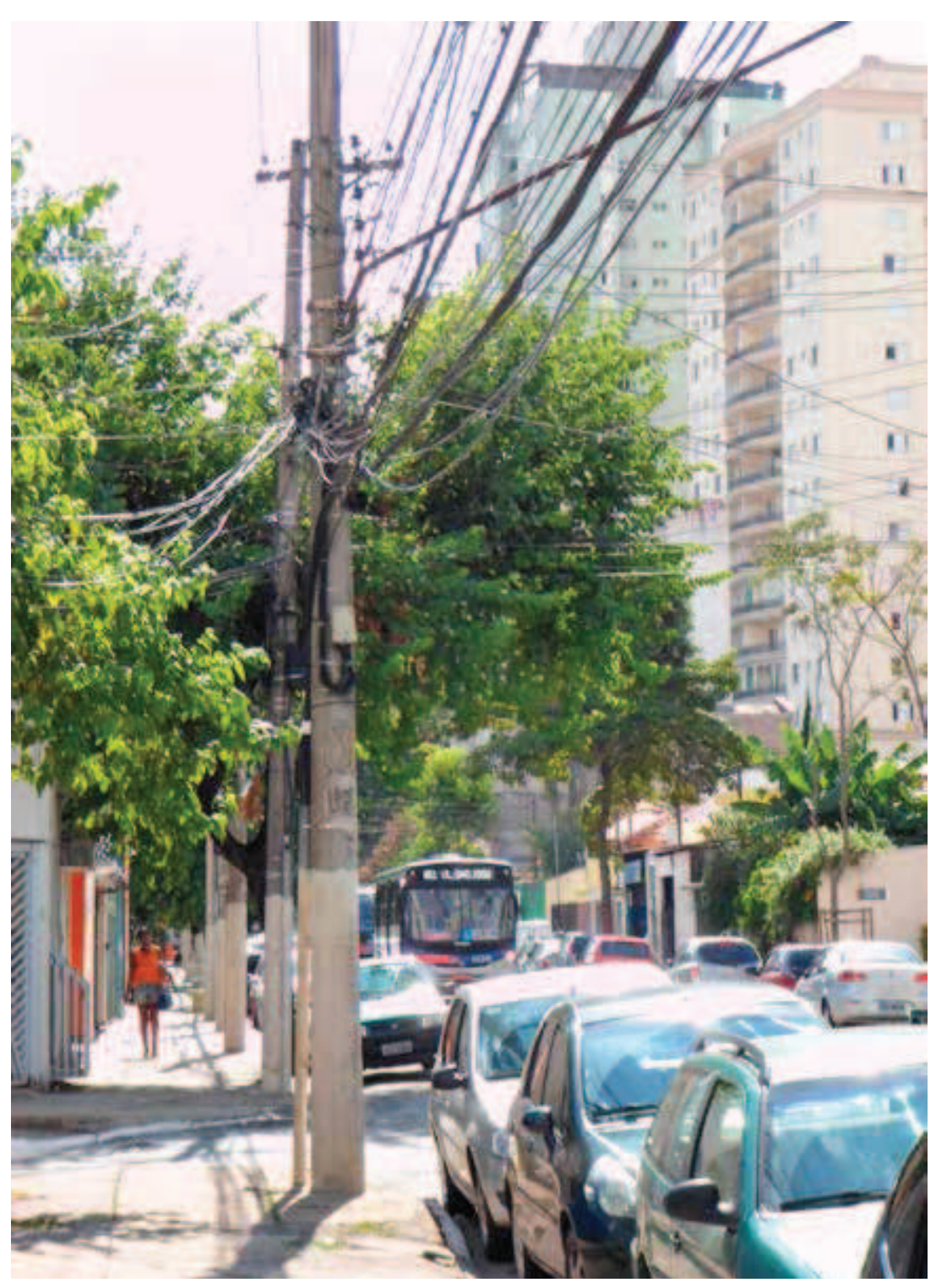

Figura 1b Conflitos aéreos e subterrâneos com a arborização. Rua Ibituruna, Parque Imperial, São Paulo (SP).

Foto: Roberto Vignola Junior - 2014

Nessas circunstâncias, acabaram por configurar-se excessivamente pavimentadas, com tubulações que cortam o subsolo e fiações de redes de telefonia, televisão, Internet e eletricidade cortando o espaço aéreo vizinho às edificações.

Com tanta disputa pelo espaço aéreo e subterrâneo no sistema viário, cada vez mais concorrido e oneroso, teme-se que seu congestionamento com tantos elementos dificulte a existência e a permanência das árvores, inviabilizando o plantio de suma importância para a qualidade de vida dos habitantes.

Spirn (1995, p. 207) aponta que o surgimento e a proliferação da arborização de rua, desde o fim do século XVI, marcou um período de rápidas mudanças na 
sociedade urbana europeia. Em seu entendimento, "[...] a história da árvore na rua fornece uma ideia da evolução da cidade e esclarece as diferenças culturais entre os países".

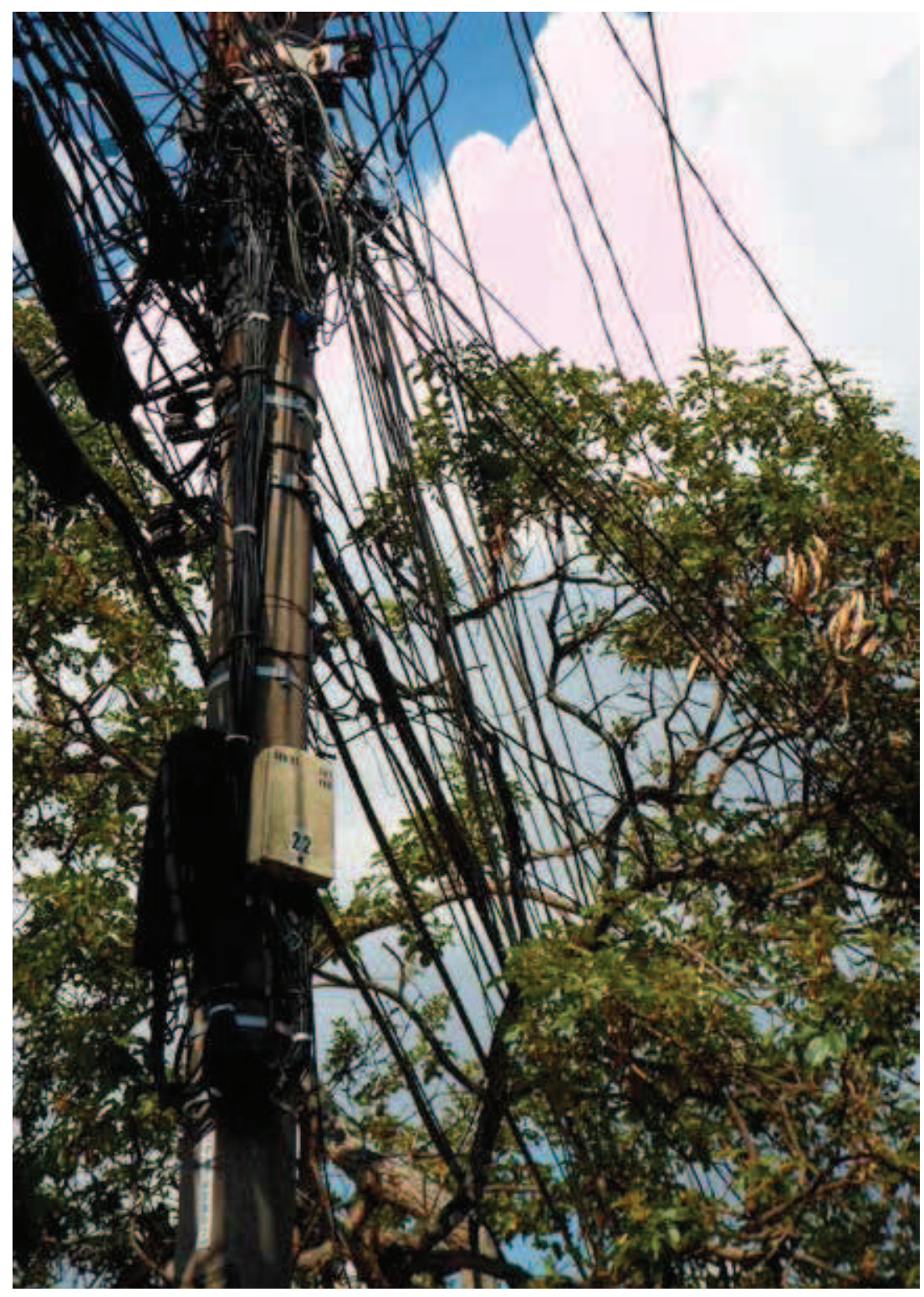

Figura 1c Conflitos aéreos e subterrâneos com a arborização. Rua lbituruna, Parque Imperial, São Paulo (SP).

Foto: Roberto Vignola Junior - 2014

Terra (2004, p. 27), no ensaio "Influências externas para a arborização no Brasil", destaca a presença da arborização nos diversos períodos históricos, acentuando a influência de diversos países, com suas características projetuais, para a paisagem das cidades brasileiras. Observa a importância da árvore ligada desde o ideal do campo da contemplação ligada ao ideal literário e filosófico, da preocupação com o cultivo 
de espécies úteis - passando pelas diversas formas de incorporação da arborização nas cidades nos vários momentos históricos, com reflexos no contexto atual, em que: "[...] o homem se conscientiza cada vez mais da importância da natureza".

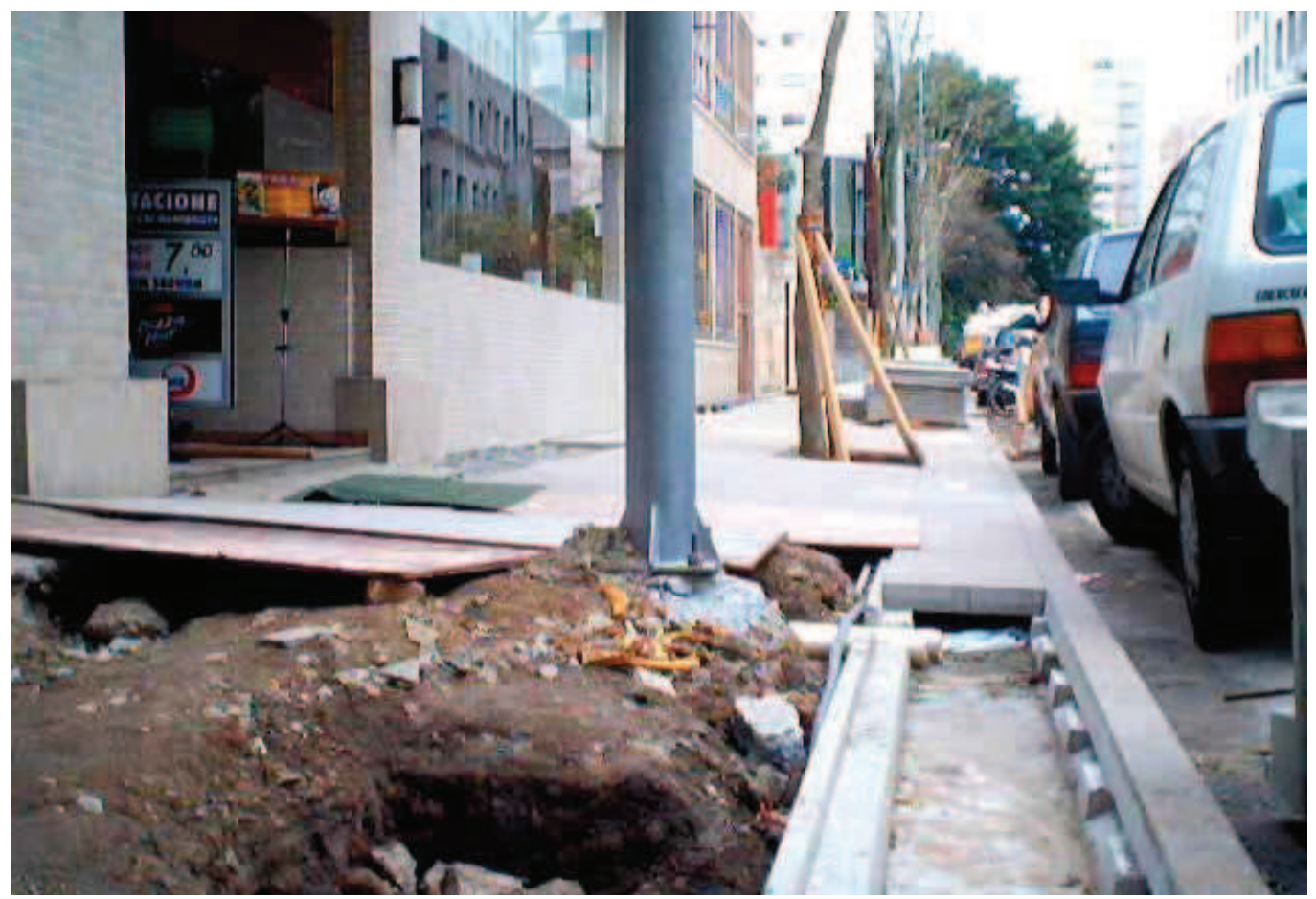

Figura 1d Conflitos aéreos e subterrâneos com a arborização. Rua Amauri, Jardim Europa, São Paulo (SP). em ruas da cidade de São Paulo.

Fonte: Roberto Vignola Junior - 2014

Diversas correntes de pensamento e movimentos sociais surgidos nos últimos anos reivindicam proteção ambiental e mudança de hábitos e valores. Entre esses movimentos, cada vez mais se reforça a preocupação com a sustentabilidade, com preferência por processos "naturais" aos "artificiais".

Particularmente com relação à necessidade de utilização de sistemas de refrigeração em ambientes prediais, também a arborização de vias públicas pode ser de grande valia. $\bigcirc$ estudo de uma correta disposição arquitetônica de barreiras de árvores, ou de seu dossel, pode amenizar o calor indesejável, suprimindo a recorrência a fontes de energia dispendiosas e cada vez mais escassas. (VIGNOLA, 2005).

\section{A ARBORIZAÇÃO EM VIAS PÚBLICAS}

A noção de arborização em vias públicas comporta, simultaneamente, duas dimensões: ambiental-ecológica e estético-modeladora da paisagem.

Para as pessoas, a arborização no sistema viário pode trazer consequências das mais diversas de acordo com o contexto em que incide, como sombreamento excessivo, dificuldades com a manutenção fitossanitária, limpeza e medidas corretivas por danos 
estruturais - destruição de calçadas e muros por raizames, queda de galhos sobre veículos. Como encontramos em Spirn (1995, p. 294), "o que se espera [na cidade] é a relação de equilíbrio entre as amenidades da sociedade e as da natureza".

Aparentemente, a maioria das pessoas prefere ruas bem planejadas e arborizadas, com oferta de melhores espaços urbanos, com qualidades físico-ambiental-estéticas estimulantes às boas condições de uso - e as árvores têm grande influência nessa qualificação, pelos seus atributos estéticos e ambientais.

O próprio mercado imobiliário constantemente dá mostra dessa importância, com slogans apelativos valorizando a arborização e os espaços ajardinados como sonhos de consumo. Quando o lançamento imobiliário é feito em rua arborizada, esse aspecto torna-se amplamente destacado pela publicidade. É comum notar que mesmo os provisórios estandes de venda apresentam vegetação de porte e cuidada. Para isso, alguns empreendedores até procuram arborizar suas calçadas para tornar os lançamentos mais atrativos.

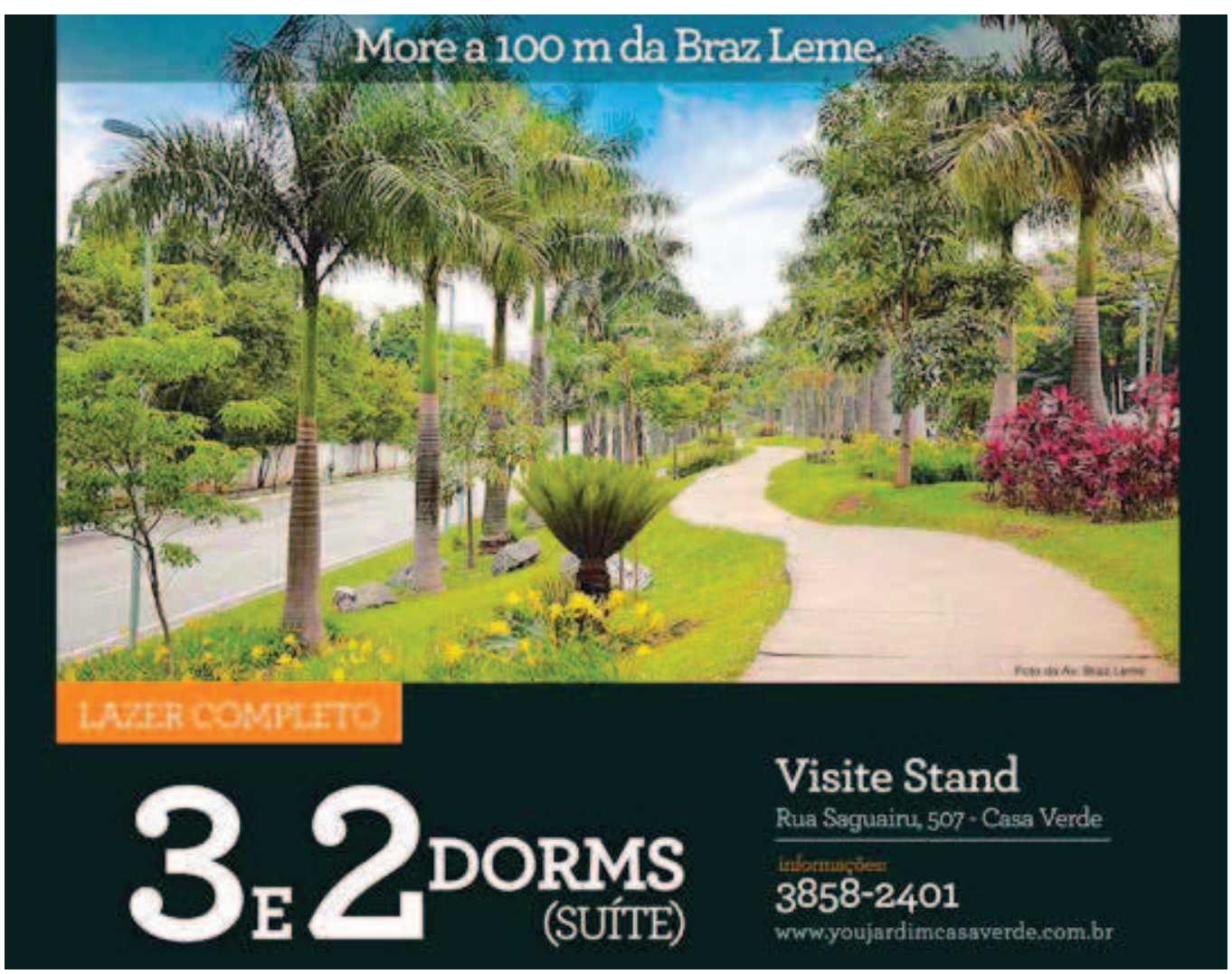

Figura 2 Anúncio valoriza o empreendimento pela proximidade à avenida arborizada com tratamento paisagístico. Fonte: $\bigcirc$ Estado de São Paulo, 24 mar. 2012, p. A32.

Sobre o esforço para conseguir boa qualidade para os espaços urbanos, Gehl (2013) aponta como essencial o planejamento cuidadoso para criar oportunidades de encontro entre as pessoas em oportunidades variadas de ver, ouvir e falar. Nesse âmbito, outras atrações - como árvores, água, flores, fontes e arquitetura - são essenciais 
no planejamento de "boas vistas" da paisagem urbana. Reforçando essa afirmação, argumenta também que: "[...] a maioria das pessoas escolhe ruas cheias de vida e atividades". (GEHL, 2013, p. 25).

De forma mais abrangente, podemos ampliar nossa discussão com o entendimento de que a introdução de árvores nas cidades é feita procurando atender questões projetuais e ambientais e influenciando o padrão de uso em regiões e áreas urbanas específicas. Pode-se inferir, também, que a arborização nos espaços livres urbanos deve ser propícia à dimensão humana, pois a presença de árvores é, em si, importante para a qualidade do espaço urbano, na medida em que as pessoas as apreciam, usufruem e se sentem reconfortadas na presença delas.

Mas árvores não existem no espaço urbano a esmo. Não prescindem da vontade da sociedade, do planejamento, da proteção, do monitoramento e da manutenção. Mesmo com tantas campanhas para a introdução de mais árvores nas ruas da cidade, uma parcela significativa não resiste muito tempo após o plantio. Com relação às árvores mais antigas, muitas vezes justifica-se a necessidade de podas e até de remoções por estarem sujeitas aos riscos de acidentes por queda. No entanto, dado o vulto, o porte e a dinâmica inerentes à arborização pertencente ao sistema viário público, é importante ter, minimamente, noções quantitativa e da sua distribuição na rede de vias da cidade, de modo a facilitar seu planejamento e gestão.

\section{GESTÃO}

A gestão e a implementação da arborização urbana dentro do sistema de espaços livres públicos de qualquer cidade são atribuições do poder público. Para a gestão pública, em se tratando de manutenção de espaços livres urbanos -, tendo em vista que o entendimento de que um dos objetivos da administração municipal é permitir melhor qualidade de vida -, a presença de árvores é, em si, um fato importante para qualificar o espaço urbano, sendo uma questão vital dentro do processo de conhecer o objeto a ser trabalhado. Este trabalho foi desenvolvido para contribuir com esse conhecimento.

O conhecimento do seu status físico-quantitativo se impõe como desafio tanto pela complexidade quanto pelo vulto. A excessiva diversidade de informações possíveis e necessárias - tais como saber onde estão e quantas são as árvores na cidade, como são suas configurações formais, suas características no sistema viário urbano - evoca a necessidade de equacionamentos que permitam a visão suficientemente precisa para o enfrentamento do problema.

Para tanto é necessário reduzir tal complexidade a fatos simples, o que tanto pode ser feito por meio de mapas, tabelas e gráficos que permitam a visualização rápida da totalidade e o fácil entendimento dos problemas em pauta, como a escassez de arborização nesta ou naquela via, neste ou naquele bairro. Portanto, considera-se fundamental a simplificação, a redução a expressões mais simples dos fatos, das suas complexidades, pois este procedimento permitirá elucidar a compreensão com base em parâmetros que nos permitam manejar melhor seus elementos. 
A primeira forma de conhecer a arborização está no cômputo de sua distribuição. Quando nos propomos ao seu cômputo em vias públicas, nos deparamos com outras questões, tais como:

- as condições de suporte e conformação próprias das vias;

- a situação das instalações aéreas e subterrâneas;

- a presença de equipamentos e mobiliários urbanos que interferem na arborização;

- a existência de recuos e acessos das construções e outras áreas de uso lindeiras;

- a irregularidade dos passeios e canteiros;

- a diversidade de espécies encontradas, com formas variadas de crescimento e configuração de suas copas.

O princípio do cômputo tem como base a possibilidade de apurar informações, permitindo-nos conceber, de maneira conjunta, dimensões capitais de nossas vidas. Sobre essa afirmativa, Edgar Morin (2005, p. 304), em seu livro O método 2 - a vida da vida, explica que o cômputo faz parte de tudo aquilo que é um processo vivo, e nesse sentido, a informação pode ser operada como estratégia de programação, planejamento e organização. Morin assevera que "[...] o cômputo é consubstancial com toda a ação organizacional, produtora ou reprodutora, com toda a dimensão do ser vivo [...]" e, ainda, que "[...] é no e pelo cômputo que todo o ato vivo se organiza".

\section{COMPUTAR COM REDUÇÃO A EXPRESSÕES MAIS SIMPLES}

Não é possível ao ser humano enxergar a complexidade sem as lentes da redução para computá-la, pois não se pode ver tudo ao mesmo tempo. Também nesse sentido, Morin (2005, p. 154) ensina que "[...] qualquer grande ideia desenvolve-se sobre duas vertentes, a complexidade e a redução".

Para o cômputo da arborização presente nos espaços livres públicos associados ao sistema viário de cidades como São Paulo, com aproximadamente 16 mil quilômetros de vias, torna-se vital reduzir a sua complexidade às expressões mais simples dos valores relacionados à arborização de vias públicas, como meio de sistematização do trabalho organizacional e de planejamento. Esse é um dos objetivos deste método: sistematizar as informações da vida vegetal arbórea existente ao longo do sistema viário ao alcance do conhecimento do planejador, do administrador público, do cidadão.

\section{ALCANCE DA INFORMAÇÃO}

Por esta razão adotou-se como critério básico que a relação fundamental discricionária que será feita entre o observador e o objeto de cômputo, o elemento arbóreo, não será pela singularidade dos indivíduos e sim pelo seu caráter genérico. Isso significa que, em princípio, deveremos simplificar a informação para saber se a via é ou não arborizada, se tem ou não tem árvore, ou seja, uma relação binária da informação 
e, a partir daí, estabelecer parâmetros de proporção por geometria convenientes à nossa compreensão.

\section{A QUESTÃO QUANTITATIVA}

Quando deparamos com a questão quantitativa da arborização de vias públicas da cidade de São Paulo, tão extensa e diversa, verificamos que esta pode ser resolvida com auxílio de técnicas de Sistema de Informação Geográfica (SIG).

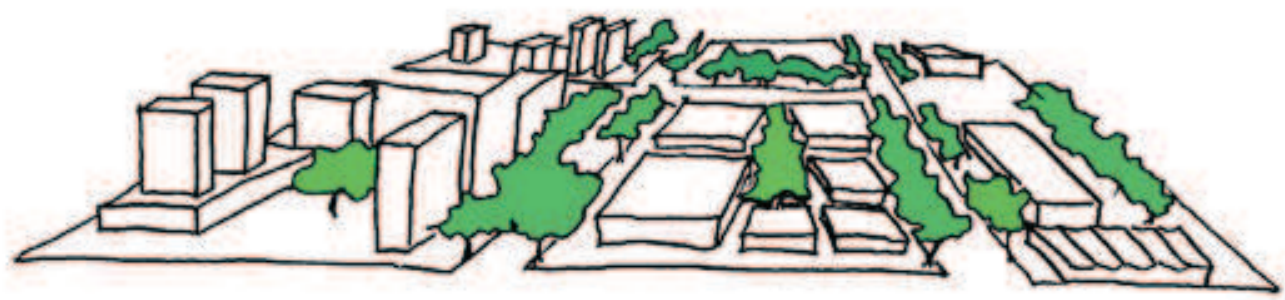

Figura 3 Desenho com destaque para as possibilidades de posicionamento das árvores e de suas copas em um contexto urbano.

Fonte: Roberto Vignola Junior - 2014

No tocante à formação de teto verde, de acordo com aspectos dimensionais do seguimento viário, vias mais largas dificilmente permitirão a total cobertura por dossel arbóreo, mesmo com a presença de árvores de grande porte (figura 4). Em vias mais estreitas, quando as condições de infraestrutura forem favoráveis, as árvores conseguirão formar plenamente um teto verde (figura 5).

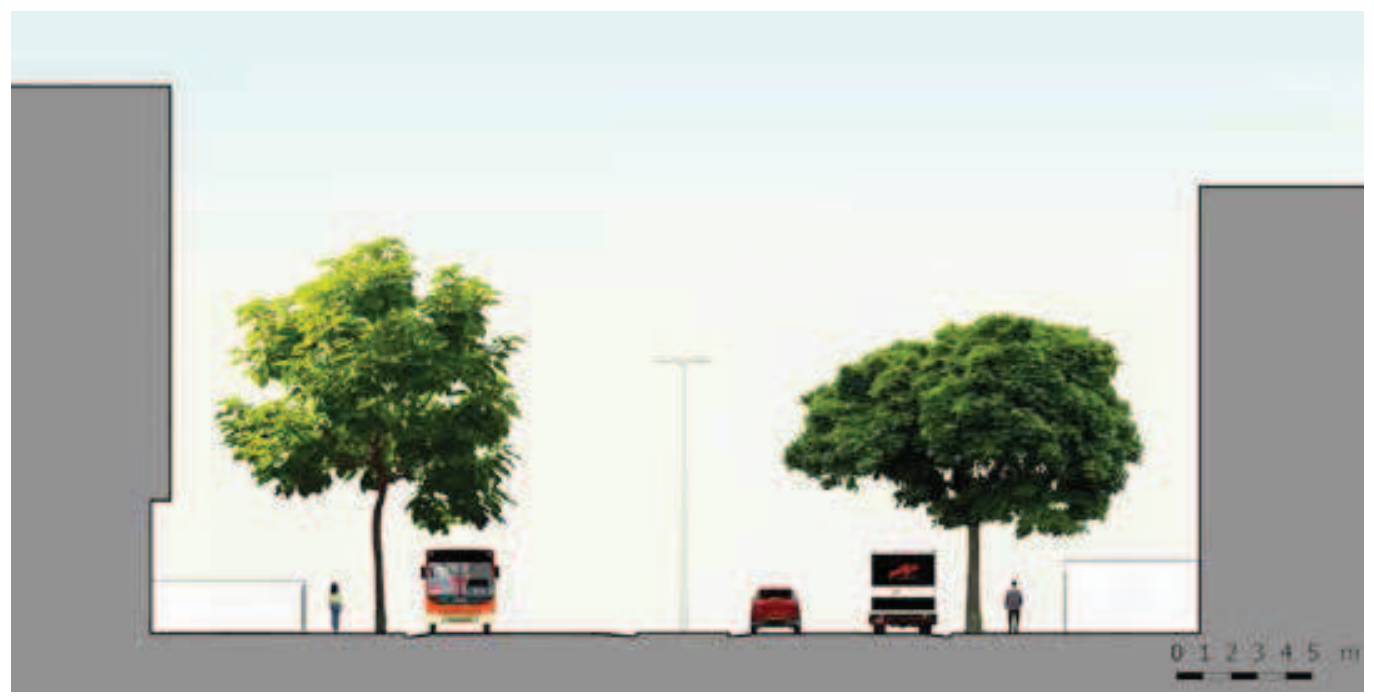

Figura 4 Desenho de avenida larga com árvores de grande porte recobrindo parcialmente a área de domínio da via.

Fonte: Roberto Vignola Junior - 2014 


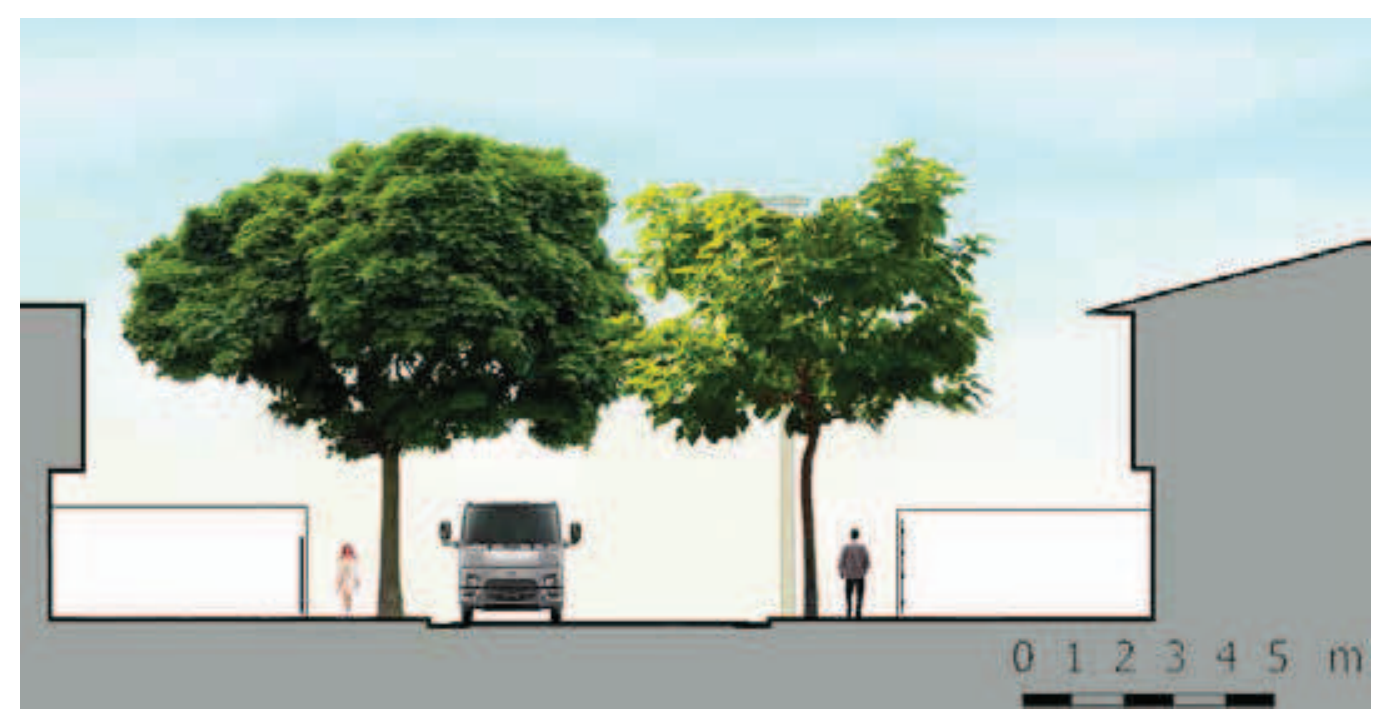

Figura 5 Desenho de rua estreita com árvores de médio a grande porte formando teto verde pleno sobre toda a área de domínio da via e parte dos recuos das construções lindeiras.

Fonte: Roberto Vignola Junior - 2014

Para um trabalho de mapeamento dessa envergadura, o uso do sistema de banco de dados geográficos viabiliza operações de análise e consulta utilizando caracterizações de interesse para a arborização. Com a convenção de atributos para identificação, por exemplo, de percentuais de sobreposição com cobertura arbórea em relação a determinados trechos do sistema viário urbano, é possível enfatizar a intensidade com que a arborização está ou não presente nos mesmos.

A questão que surge, e conceitua este trabalho, é a consideração sobre o dossel arbóreo como conjunto de coberturas formadas pelas copas das árvores ao longo do sistema viário, porém com priorização unidimensional (longitudinal), e não propriamente pela área de cobertura. Este significado dinamizará o processo de identificação e permitirá sua avaliação.

O uso do SIG, neste caso, será feito pela associação de imagens de satélite (ou foto aérea) com apoio de análise nas fotos do sítio eletrônico Google Maps Street View. Pretende-se entender onde existem árvores, com que frequência aparecem e em que tipo de vias. Dependendo do grau de resolução da imagem de satélite e de acordo com a aproximação necessária para visualização de detalhes de cada indivíduo (árvore), muitas vezes não é possível ver, com observação a olho nu, além da totalidade do conjunto arbóreo.

Considerando essa dificuldade, pelo método ArbVias avalia-se o conjunto da arborização ao longo do sistema viário urbano sem a necessidade de saber como são os indivíduos e sua exata localização. Importa é saber quais são as áreas contínuas, ou não, formadas pelas copas das árvores, de modo a construir mapas temáticos que permitam diagnósticos de quais vias devem ser priorizadas em processos de manejo da arborização. 


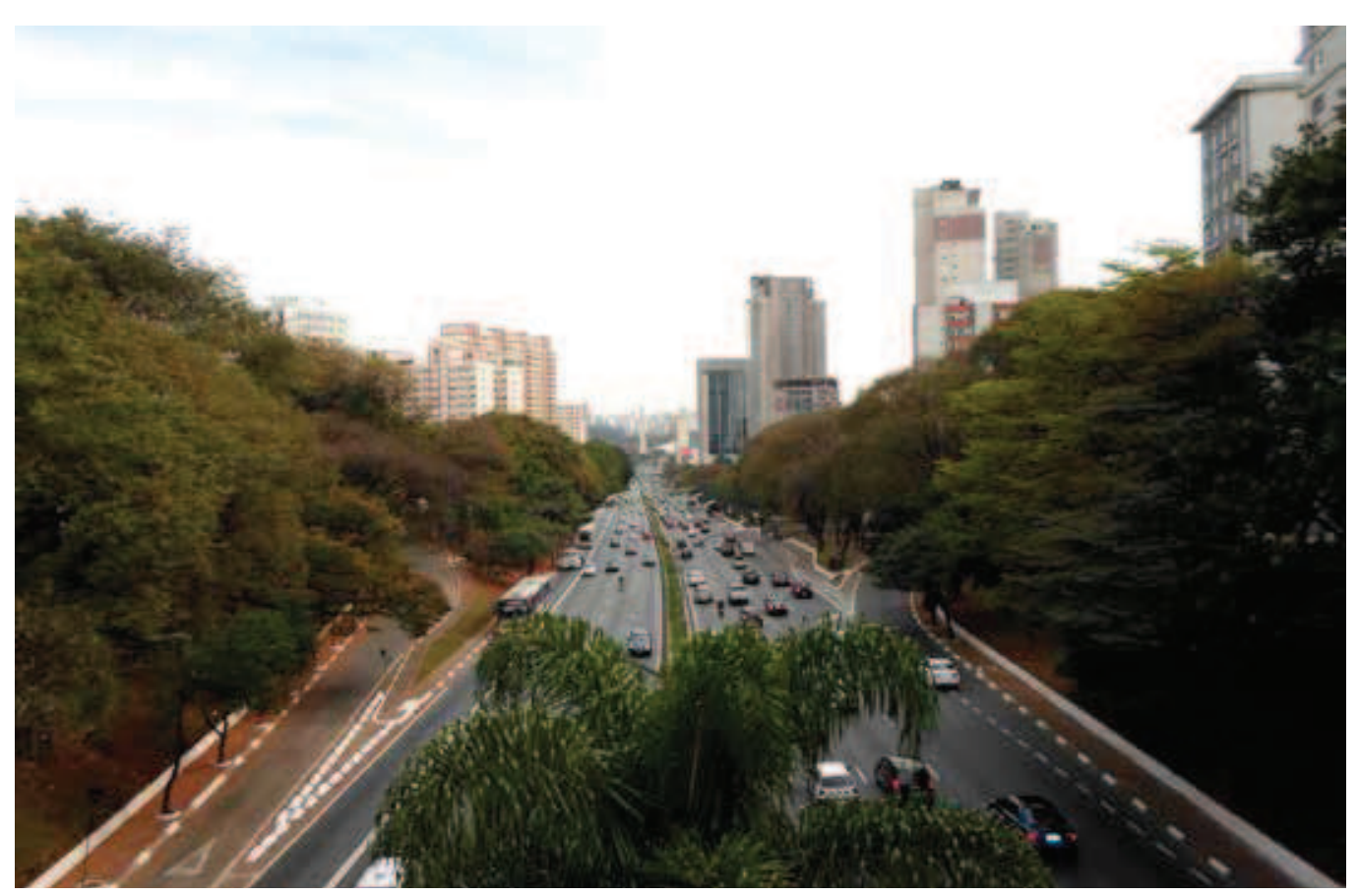

Figura 6 Avenida 23 de Maio, em São Paulo (SP), vista do viaduto da rua Cubatão. Com intensa arborização, mostra como é difícil a leitura de detalhes dos indivíduos (árvores) além da superfície externa do dossel. Foto: Roberto Vignola Junior - 2014

\section{MODELAGEM CONCEITUAL - CONSTRUÇÃO CONCEITUAL DOS DADOS GEORREFERENCIADOS DO MÉTODO}

Tendo em vista a diversidade de fontes de informação sobre arborização, que podem ser encontradas em mapas, em plantas cadastrais, tabelas, foi necessário avaliar a pertinência das informações disponíveis para a utilização neste trabalho. Isso resultou na criação de um novo campo de dados, denominado ArbVias, que incorpora os atributos relacionados à qualificação da arborização finalizados em mapeamento temático. Para tanto julgou-se mais adequado seguir algumas recomendações sobre modelagem conceitual para melhor exprimir a base formal do esquema de trabalho adotado. Entre as possibilidades várias de linguagens adotamos o modelo proposto por Peter Chen (1976 apud Lisboa, 2001), entendendo-o como recurso semântico de fácil interpretação, como classifica Lisboa (2001), por possuir notação gráfica bastante simples e de fácil aprendizado.

Assim, neste trabalho, com vistas a mostrar o que é pertinente para o método, foram priorizadas as entidades ${ }^{2}$ principais, com os respectivos relacionamentos ${ }^{3}$ e cardinali-

2 Todo fenômeno, com existência física ou conceitual, é representado como uma Entidade. Neste experimento, as Entidades foram identificadas como: aerofoto, ortofotocarta do município, regiões administrativas (subprefeituras), distritos, quadras, malha viária, seguimentos dos logradouros, atributos ArbVias.

3 Relacionamento $(1, N, M)$ representa o número de entidades às quais outra entidade ou outras entidades se associam. 
dades $^{4}$, representados conforme o Diagrama Lógico Entidade-Relacionamento (E-R), descrito a seguir (figura 7), como forma de representação computacional dos dados espaciais a serem georreferenciados.

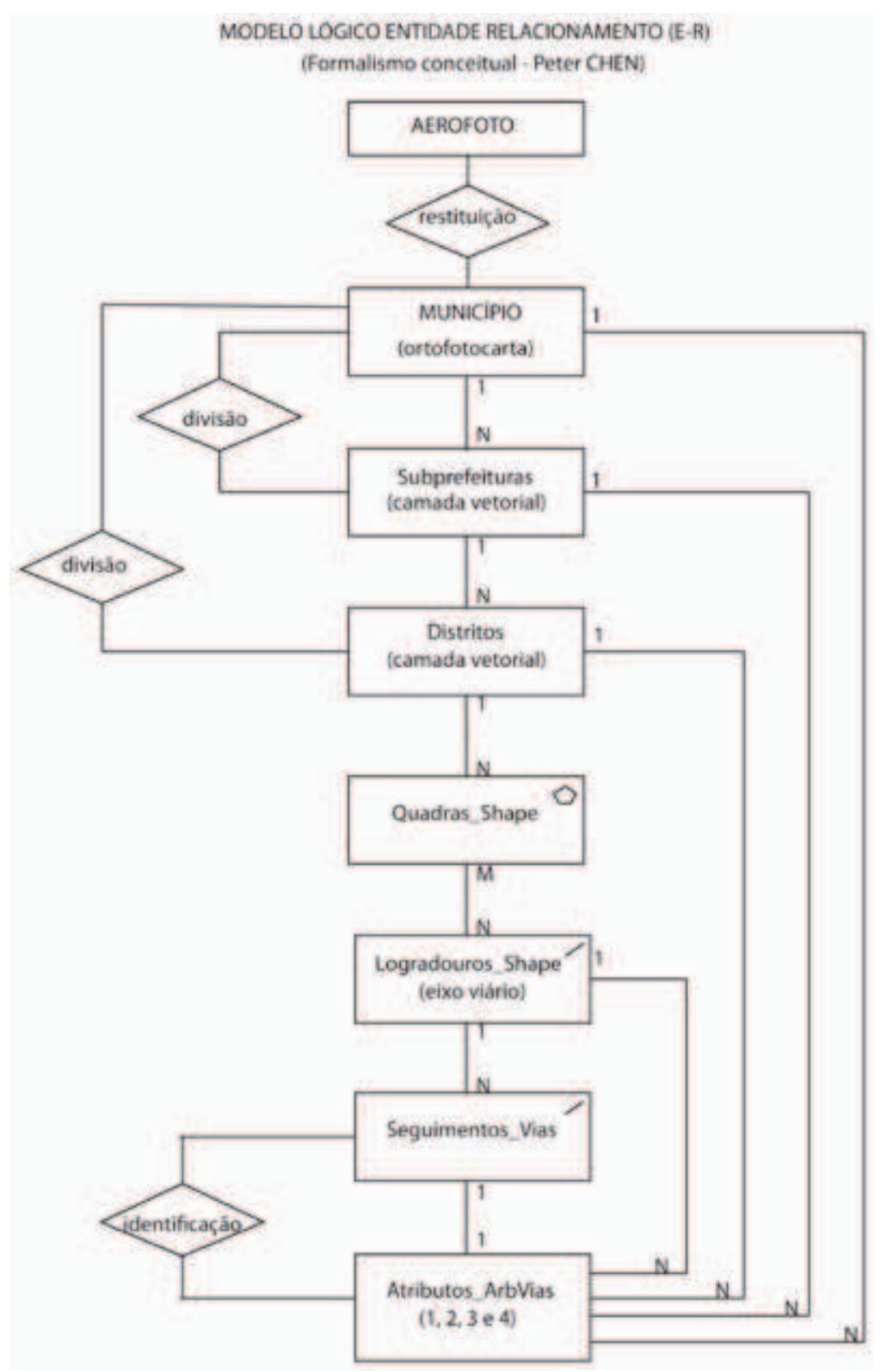

Figura 7 Diagrama Lógico Entidade-Relacionamento. Fonte: Roberto Vignola Junior - 2014

Cabe salientar que um SIG não é um banco de dados pronto. $O$ usuário é, em parte, responsável pela sua criação, o que equivale a dizer que o sucesso deste tra-

4 A cardinalidade no relacionamento $E-R$ indica o número de entidades às quais uma outra entidade pode estar associada via relacionamento. Pode ser: um para um (1:1), um para muitos (1:N), muitos para muitos (M:N). 
balho começa com a eficiente modelagem de banco de dados, com chave primária ${ }^{5}$ convencionada - que permita associações com outros bancos de dados - e chaves secundárias que permitam, por exemplo, eventual segregação de vias por categorias, com dimensionamentos relevantes (extensão, largura, largura de passeios) e identificação de infraestrutura na via. Um SIG inclui software, hardware, dados e pessoal.

Comumente, bancos de dados com informações importantes sobre o sistema viário são inviabilizados por estarem subordinados a entidades fracas, tais como os nomes dos logradouros apresentados com grafia diferenciada e sem distinção de homônimos.

O objetivo maior deste trabalho é possibilitar nova forma de visualização para orientar estratégias de implantação e gestão da vegetação de porte arbóreo nos espaços livres constituídos pelo sistema viário público urbano.

Como expectativa em relação ao uso do geoprocessamento é almejada a potencialização para correlacionar esses resultados da pesquisa ArbVias com outros dados georreferenciados que possam interferir positiva ou negativamente com o processo de arborização em vias públicas.

Outros objetivos são:

- compreender a distribuição da arborização no sistema viário;

- determinar a distribuição por faixas de adensamento, considerando o dossel arbóreo segundo quatro categorias predefinidas e de interesse para o estudo;

- correlacionar outras ocorrências passíveis de representações computacionais relacionadas ao fenômeno estudado, tais como: largura da via, largura dos passeios, existência de infraestrutura aérea ou subterrânea, predominância de recuos das edificações, predominância construtiva e uso do solo;

- verificar a viabilidade de compartilhamento desses dados com outros estudos, tais como: microclimáticos, geológicos e geotécnicos.

\section{SOBRE O MÉTODO ARBVIAS}

O método surgiu a partir de estudos sobre a arborização de vias públicas, dentro da pesquisa "Arborização e vias públicas", que mostravam a necessidade de avaliação quantitativa e de visualização dessa distribuição de maneira ampla, ágil e versátil.

Os primeiros ensaios desta pesquisa foram realizados com apoio em hardware convencional $^{6}$ e nos softwares GIS TerraView e ArcGIS. Porém, em virtude de algumas limitações encontradas, verificou-se a necessidade de novas adaptações, cujas rotinas de operação melhor se adaptaram com os softwares QGIS - Quantum GIS

A chave primária é o atributo que identifica univocamente cada entidade em um conjunto de entidades, a exemplo do ID e CODLOG.

6 Os meios para coleta, tratamento e processamento de dados incluíram características mínimas para o hardware, com o uso de equipamentos de pequeno porte, com plataforma PC, sistema operativo, memória, processador e placa gráfica suficientes para leitura e manipulação de arquivos digitais, gráficos e dados alfanuméricos. 
versão 1.8 Lisboa, principalmente para a incorporação de atributos em escalas de avaliação e compilação de resultados por totalização de extensões.

Uma das vantagens de aplicações da metodologia com softwares como o Quantum $\mathrm{GIS}^{7}$ é o fato de ser um software livre. Entre outras vantagens estão a facilidade no relacionamento entre DATUM ${ }^{8}$, a rapidez e facilidade com que as fotos de satélite são georreferenciadas e a associação fácil com outros programas livres, como linux, libreoffice e OpenJUMP. Com relação aos aplicativos "plug in" oferecidos pelo Quantum GIS 1.8.0 Lisboa, foram utilizados os seguintes complementos python: Sextante; OpenLayers Plugin; DB Manager; Table Manager; QuickMultatributEdit; OpenStreetMap Plugin; Plugin Installer; MapServer Export; GdalTools.

O tipo de procedimento adotado para a análise foi o denominado Modalidade Dirigida, o qual é baseado em análise visual pelo operador. Este deverá resolver questões topológicas que the permitam tipificar padrões de arborização por meio de sobreposição e recortes de compensação necessários para quantificar as projeções das copas sobre um determinado trecho de via.

Para tanto utilizou-se um mapa vetorizado com arquivo shapefile ${ }^{9}$ da cidade de São Paulo, obtido do Centro de Estudos da Metrópole (CEM) ${ }^{10}$, disponibilizado pela Prefeitura Municipal de São Paulo (PMSP), no qual a cada via são associadas uma ou mais linhas/ eixos de acordo com a quantidade de pistas existentes nas vias representadas no mapa.

Essa comparação quantitativa é feita com base em um padrão gráfico determinado para enquadramento em um dos quatro atributos de qualificação da arborização na via - os atributos ArbVias com valores 1, 2, 3 e 4:

- atributo 1: correspondente à via muito arborizada;

- atributo 2: correspondente à via medianamente arborizada;

- atributo 3: correspondente à via pouco arborizada;

- atributo 4: correspondente à via sem ou quase sem arborização.

O programa Quantum Gis chegou próximo a 500 mil downloads como sistema open source, segundo publicado em Magazine for Surverying Mapping \& GIS Professionals, 8 dez. 2013, volume 6 - GEO informatics, p. 45. Netherlands. Disponível em: <www.geoinformatics.com>. Acesso em: 22 out. 2012.

8 De forma simplista, DATUM, em cartografia, é um modelo matemático que representa a superfície curva da Terra em três dimensões, ajustado da forma mais conveniente em função da topografia de um determinado território, providenciando o ponto de referência relacionado aos paralelos e meridianos. Para o Brasil, as referências topocêntricas são obtidas com o DATUM SAD69 e DATUM Córrego Alegre, com seus marcos no Estado de Minas Gerais. O DATUM mais atual no Brasil é o Sistema de Referência Geocêntrico para as Américas (SIRGAS).

9 Formato vetorial originalmente desenvolvido pela empresa criadora do software ArcGIS. O shapefile é um arquivo do programa GIS que contém dados georreferenciados, que podem representar informações diversas, geometrizadas através de pontos, linhas e polígonos. Essas geometrias descrevem entidades com dados georreferenciais em forma de vetor e descritas por arquivo de atributos, tais como vias e árvores no caso em estudo.

10 Instituição financiada pela Fundação de Amparo à Pesquisa do Estado de São Paulo (Fapesp), pelo Centro Nacional de Desenvolvimento Científico e Tecnológico (CNPq) e pelo Ministério da Ciência, Tecnologia e Inovação (MCTI), por meio de um novo modelo de organização da investigação científica implementado nos Centros de Pesquisa, Inovação e Difusão (Cepids) e nos Institutos Nacionais de Ciência e Tecnologia (INCTs). 
Com o shapefile do sistema viário, tendo como objeto vetorial segmentos de eixos ou polilinhas classificadas com os atributos ArbVias, torna-se possível a produção de mapas temáticos para ilustrar a situação da arborização do sistema viário em determinada região da cidade.

A ideia é avaliar a extensão da cobertura das copas das árvores presentes em determinada via pela somatória de suas projeções sobre nova forma (shape), representada com geometria linear, cujo resultado será objeto de aferição conforme os padrões convencionados pela metodologia. Para tal se converte geometria plana em geometria linear. As formas bidimensionais das copas das árvores visualizadas na imagem de satélite sobre determinada via, projetadas ortogonalmente sobre seu eixo (shape), passam a assumir a nova representação reduzida do dossel arbóreo ao longo do sistema viário na forma de seguimentos lineares. Abaixo, o procedimento para análise adotado:

1) todo o trabalho se dá sobre um mapa de vias da cidade vetorizadas, que é um shapefile de vias, disposto sobre uma imagem de satélite" (ou foto aérea) georreferenciadas;

2) sobre cada via do mapa identifica-se, sobre sua área de domínio, um eixo central, representado com feição geométrica polilinha, que será o referencial de análise; no caso de uma avenida com canteiro central, para cada pista poderá corresponder uma polilinha, sendo possível, assim, encontrar vias representadas com uma, duas ou mais polilinhas;

3) esta linha ou polilinha estará associada a uma escala de medição em porcentagem, que permite dizer o quanto de cobertura arbórea existe no trecho urbano em pauta; em cada trecho da via será feita associação, em porcentagem da continuidade de copas de árvores existentes, com faixa de porcentagem correspondente a uma cor, conforme legenda; cada faixa receberá um atributo de 1 a 4, que corresponde a um valor em porcentagem da soma das extensões de dossel arbóreo em proporção ao comprimento do eixo da via ou seguimento de via analisado de acordo com a tabela que se segue:

- atributo 1: extensão do eixo com $90 \%$ a $100 \%$ coberto com copas;

- atributo 2: extensão do eixo com $50 \%$ a $90 \%$ coberto com copas;

- atributo 3: extensão do eixo com $10 \%$ a $50 \%$ coberto com copas;

- atributo 4: extensão do eixo com $0 \%$ a $10 \%$ coberto com copas.

4) esse estudo de padronização se vale da adoção de padrão gráfico de referência, aqui denominado escala gráfica de aferição, para enquadramento dos quatro padrões básicos; a utilização dessa escala é um trabalho subjetivo, no qual

11 No caso foram utilizadas as imagens Google satellite 2014 disponibilizadas em Open Layers plugin do próprio programa QuantumGIS 1.8.0 Lisboa. 
o operador munido de atenção e bom senso deve utilizar sua capacidade de visualização para aferir a proporcionalidade entre as extensões do eixo da via analisada e as projeções de dossel sobre este; deve-se ressaltar que esta operação não requer grande precisão de análise, pois os resultados a serem obtidos são suficientes para compreender a situação da arborização no sistema viário; também não são requeridos valores precisos, pois mesmo pequenos desvios não são significativos - de fato as totalizações de resultados convergem para valores médios, na verdade flutuante, pois a permanência da arborização nas vias tem sua dinâmica própria, mesmo porque a escala de aferição foi concebida com valores de fácil visualização (metade, um décimo e o total menos um décimo), ou seja, não é requerido grande treinamento ou instrumental sofisticado, apenas um pouco de habilidade e predisposição;

5) o que se pretende de fato, e se mostrou válido como resultado final, é o alinhamento da impressão do que pode ser conotado como pouco, muito e mediano para menos ou para mais, em relação à quantificação do fenômeno estudado;

6) para efeito de medição (em \%) é considerada 100\% arborizada qualquer via que contenha árvores com copas contínuas em um de seus lados ou em ambos os lados, pois o que vale é a análise referenciada pelo eixo adotado (linha azul como no desenho da figura 9); se a via tiver vários eixos e canteiro central, as árvores deste serão consideradas simultaneamente para a análise de cada eixo, ou seja, os dois eixos limitados pelo mesmo canteiro central são considerados arborizados pelas mesmas árvores.

A figura 8 exemplifica, através de sequência de desenhos, casos de vias arborizadas com árvores dispostas de formas distintas, delimitando contornos distintos pela projeção de suas copas, com áreas não necessariamente iguais, em vias com dimensões diferentes, constituídas de pista única ou dupla - mas que, pelo modelo conceitual que embasa o método ArbVias, são avaliadas com o mesmo atributo. Isto é, são entendidas como vias igualmente arborizadas, no caso, com atributo ArbVias 1. Evidentemente, cada caso tem um impacto diferente.

Observa-se que, para efeito de avaliação, uma via arborizada dos dois lados não é considerada menos arborizada que uma via com arborização apenas em um de seus lados, ou uma via arborizada só no canteiro central. No caso de vias com dois eixos, será avaliado cada eixo como se fosse uma via, caso em que um dos lados da "via" poderá ser o canteiro central (figura 9). 
a

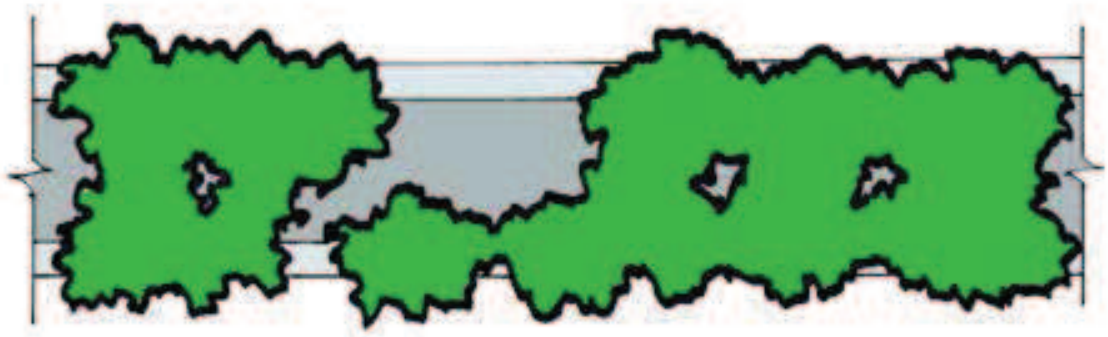

b

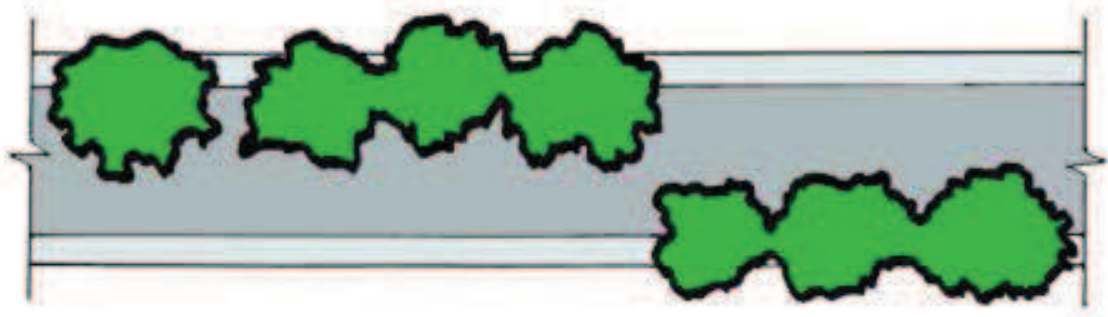

C
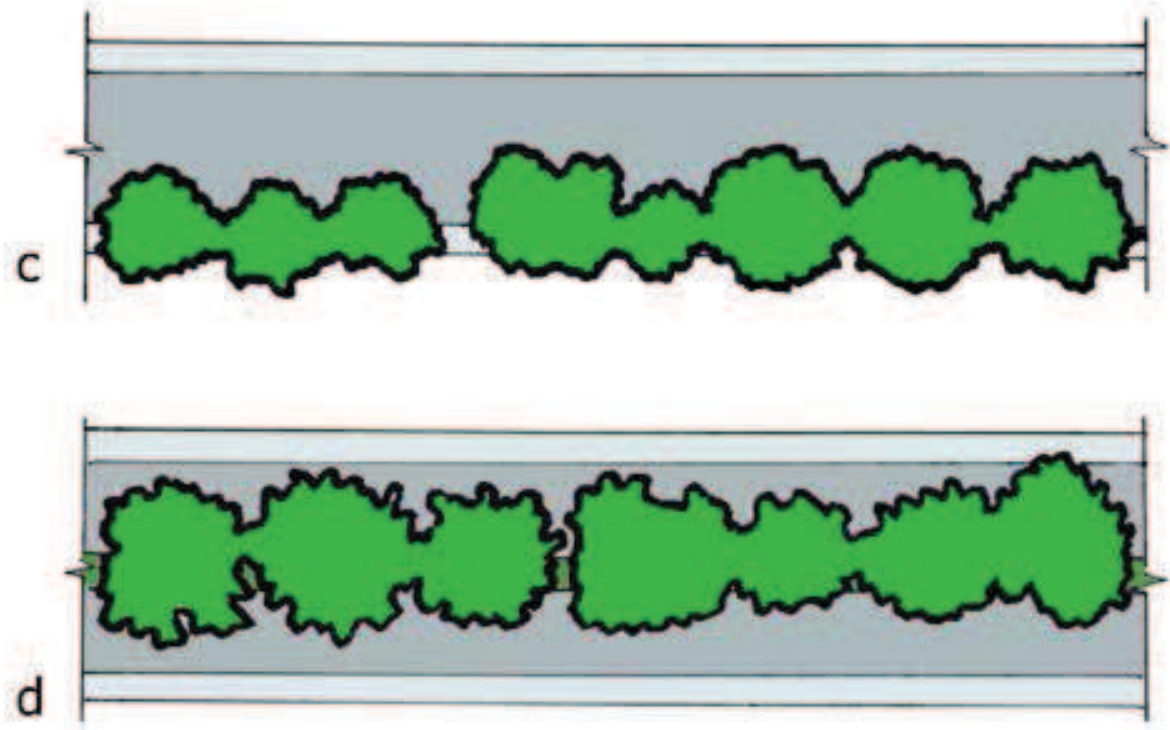

Figura 8 Quatro exemplos de vias com arborização conceitualmente classificadas com o atributo ArbVias 1: a) arborização contínua nos dois lados da pista; b) arborização descontínua nos dois lados da pista; c) arborização contínua só em um lado da pista; d) arborização contínua só no canteiro central em via com duas pistas. Fonte: Roberto Vignola Junior - 2014 

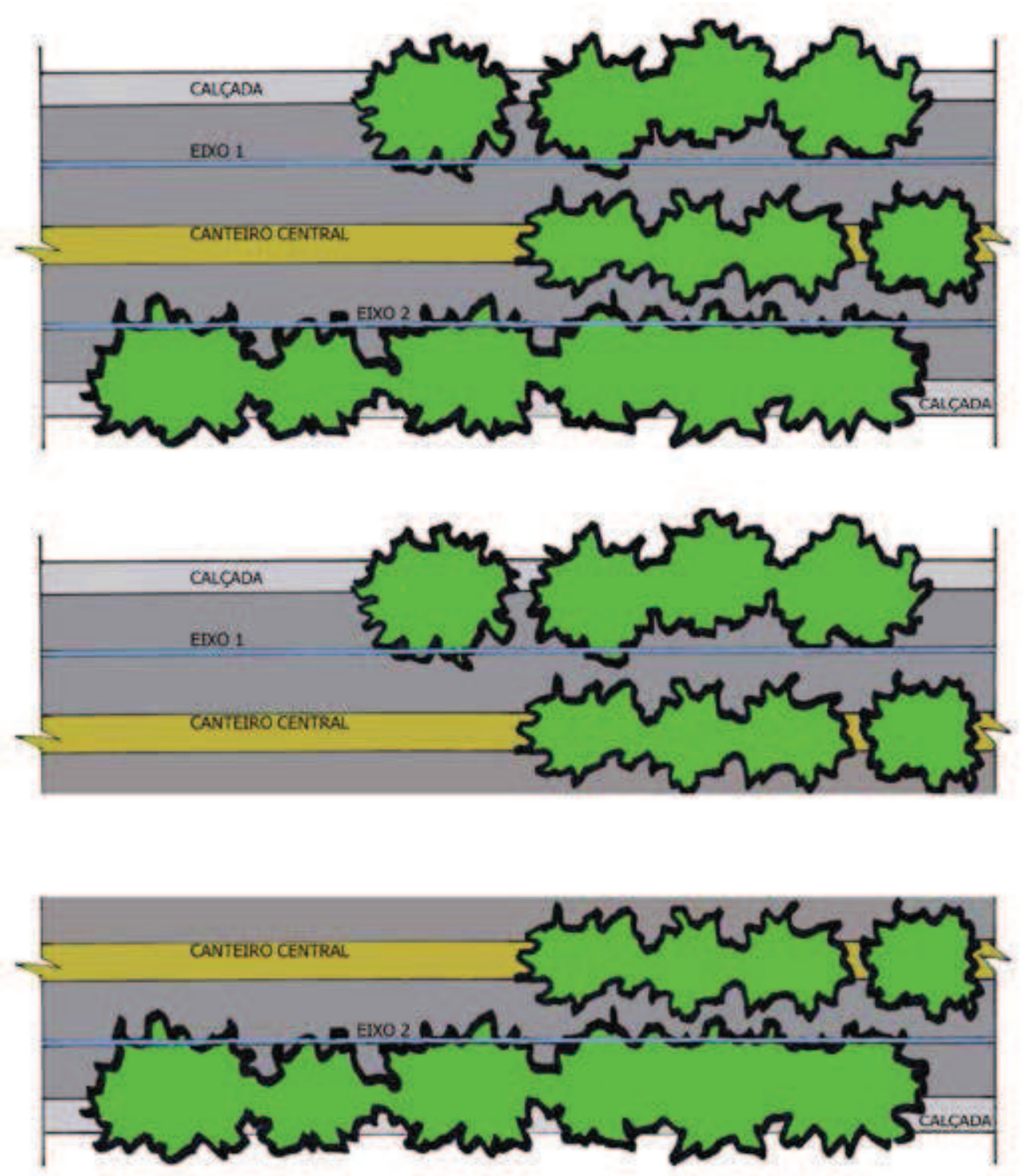

Figura 9 Desenho de via com dois eixos e divisão para análise de cada eixo separadamente. Fonte: Roberto Vignola Junior - 2014

Desenvolve-se, a seguir, um exemplo de padronização (do dossel arbóreo sobre o eixo viário) com simulação por computação gráfica dos padrões básicos de arborização comumente encontrados como referência para a interpretação da escala de padronização formalizada em mapeamento com o programa Quantum GIS.

Etapa 1: sobre um trecho de via hipotética, associa-se uma escala gráfica dividida em 10 partes iguais. A linha ao meio, em azul, é o eixo de referência para avaliação (figura 10); esta é uma simulação em um procedimento real, com o desenho da via correspondente ao de uma foto aérea hipotética; 


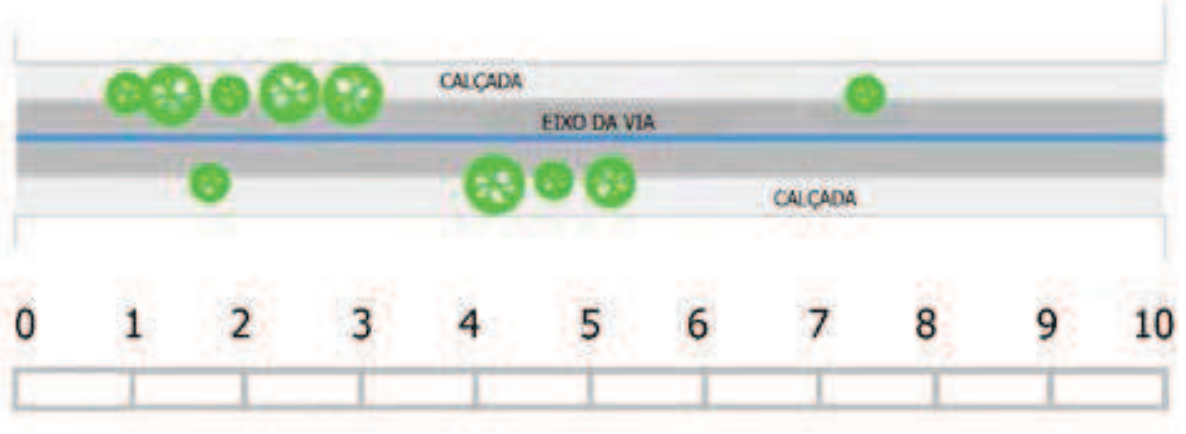

Figura 10 Desenho representativo de via, com eixo (cor azul) dividido em dez partes iguais. Fonte: Roberto Vignola Junior - 2014

Etapa 2: a cada trecho da via, ou na via inteira, é atribuído um valor referenciado na escala gráfica (dividida em 10 partes iguais) de acordo com os atributos do item 3 do procedimento de análise (figura 11).

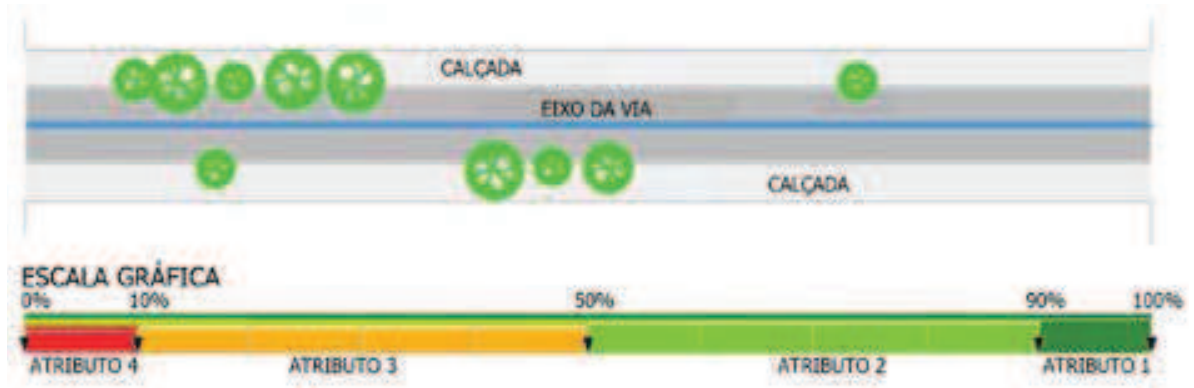

Figura 11 Desenho representativo de via arborizada e escala gráfica proporcional à extensão do eixo. Fonte: Roberto Vignola Junior - 2014

Ełapa 3: tem-se que, no segmento em questão, totalizados três trechos ocupados por arborização (E1, E2 e E3), que correspondem à extensão total "E", com aproximadamente $40 \%$ do seguimento de via no qual a área de cobertura com copas de árvores se projeta sobre o eixo da via, e que se enquadra no atributo 3, com grau de variação entre $10 \%$ e $50 \%$ da extensão do eixo do seguimento da via (figura 12 ).

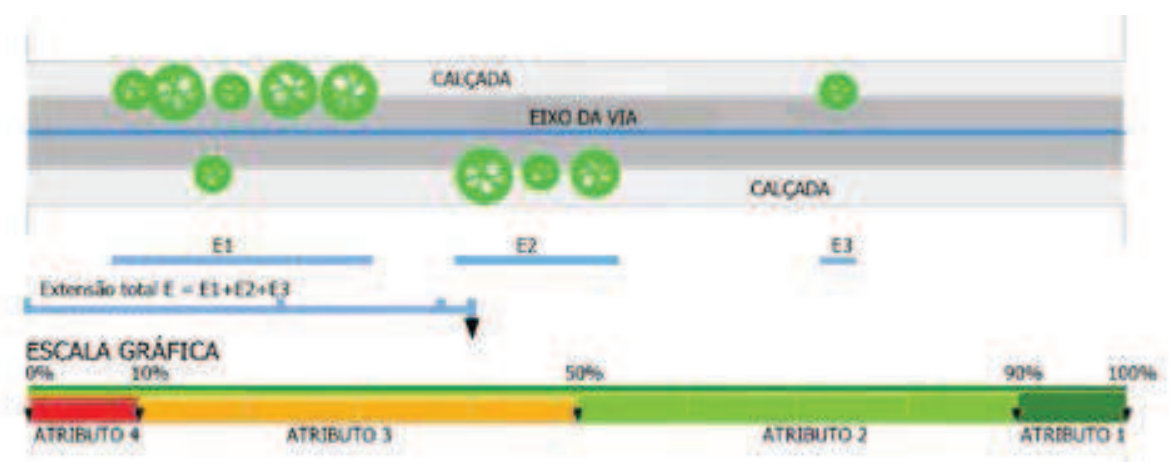

Figura 12 Desenho representativo do processo de análise para escolha de atributo ArbVias por meio da quantificação da extensão de copas de árvores projetadas sobre o eixo.

Fonte: Roberto Vignola Junior - 2014 
Etapa 4: esse resultado, de acordo com a escala gráfica, será representado no mapa de arborização com a cor laranja para o trecho de via analisado (figura 13), alterando-se a cor do eixo adotado sobre a representação do shape - com geometria de polilinha segundo legenda convencionada para esse método na cor azul.

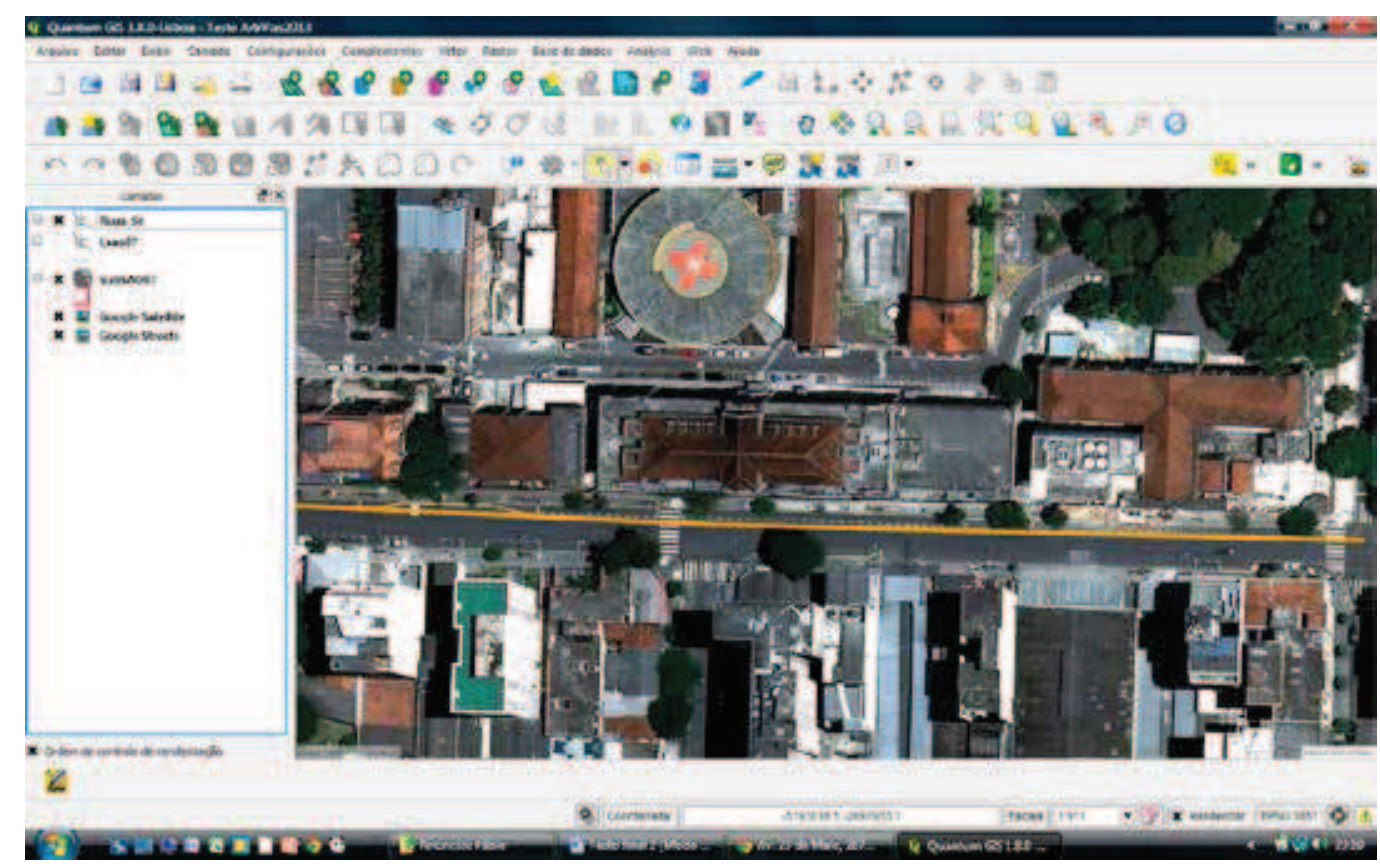

Figura 13 Exemplo de reprodução da tela de interface do programa QGIS resultante da escolha de atributos ArbVias com representação no mapa temático. Rua Marques de Itu, Vila Buarque, São Paulo (SP).

Fonte: Tela do aplicativo QGIS - 2014

\section{MAPEAMENTOS}

O exemplo seguinte mostra através de mapa temático como em um trecho da cidade de São Paulo, correspondente à Subprefeitura Butantã, a frequência de arborização do sistema viário foi representada a partir deste método (figura 14).

Através de mapas temáticos como os das figuras 14 a 18, é possível visualizar a situação geral do recobrimento das copas ao longo do eixo viário, permitindo, também, a representação selecionada por categoria ${ }^{12}$ de arborização (atributo ArbVias), e como se distribuem em uma área administrativa como a da Subprefeitura Butantã.

Além disso, esse recurso permite computar a extensão total de vias arborizadas por categorização ArbVias de acordo com os conteúdos cartográficos elaborados sobre cada mapa temático.

Servindo-se desse modo de representação, como filtro da realidade material, pode-se compreender melhor a forma como a arborização se distribui ao longo das vias, seja em área administrativa, distrito, por tipos de vias ou na cidade como um todo.

\footnotetext{
12 Com o programa QGIS pelo comando Analysis SEXTANTE toolbox.
} 
São Paulo - Arborização de Vias Públicas

Subprefeitura Butantã

Mapa temático - método ArbVias

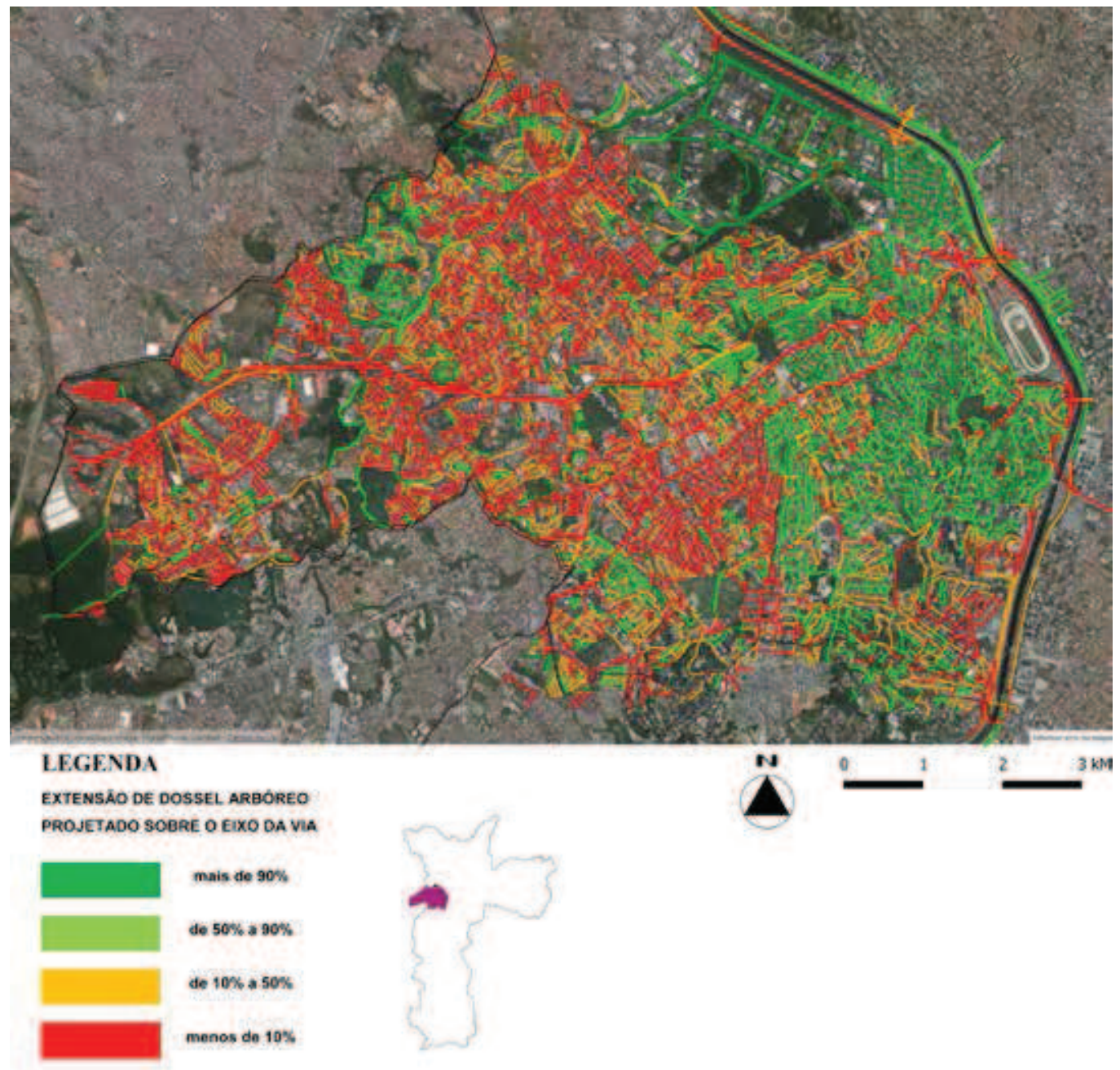

Figura 14 Mapa temático da Subprefeitura Butantã finalizado pelo método ArbVias.

Fonte: Produzido por Patrícia Eiko Aguchiku - 2014

\section{Resultados:}

Vias muito arborizadas (verde escuro) - 134,16 Km

Vias medianamente arborizadas (verde claro) - 193,33 Km

Vias pouco arborizadas (larania) - 232,54 Km

Vias sem ou quase sem arborização (vermelho) - 353,29 Km 
São Paulo - Arborização de Vias Públicas

Subprefeitura Butantã

Mapa temático - método ArbVias

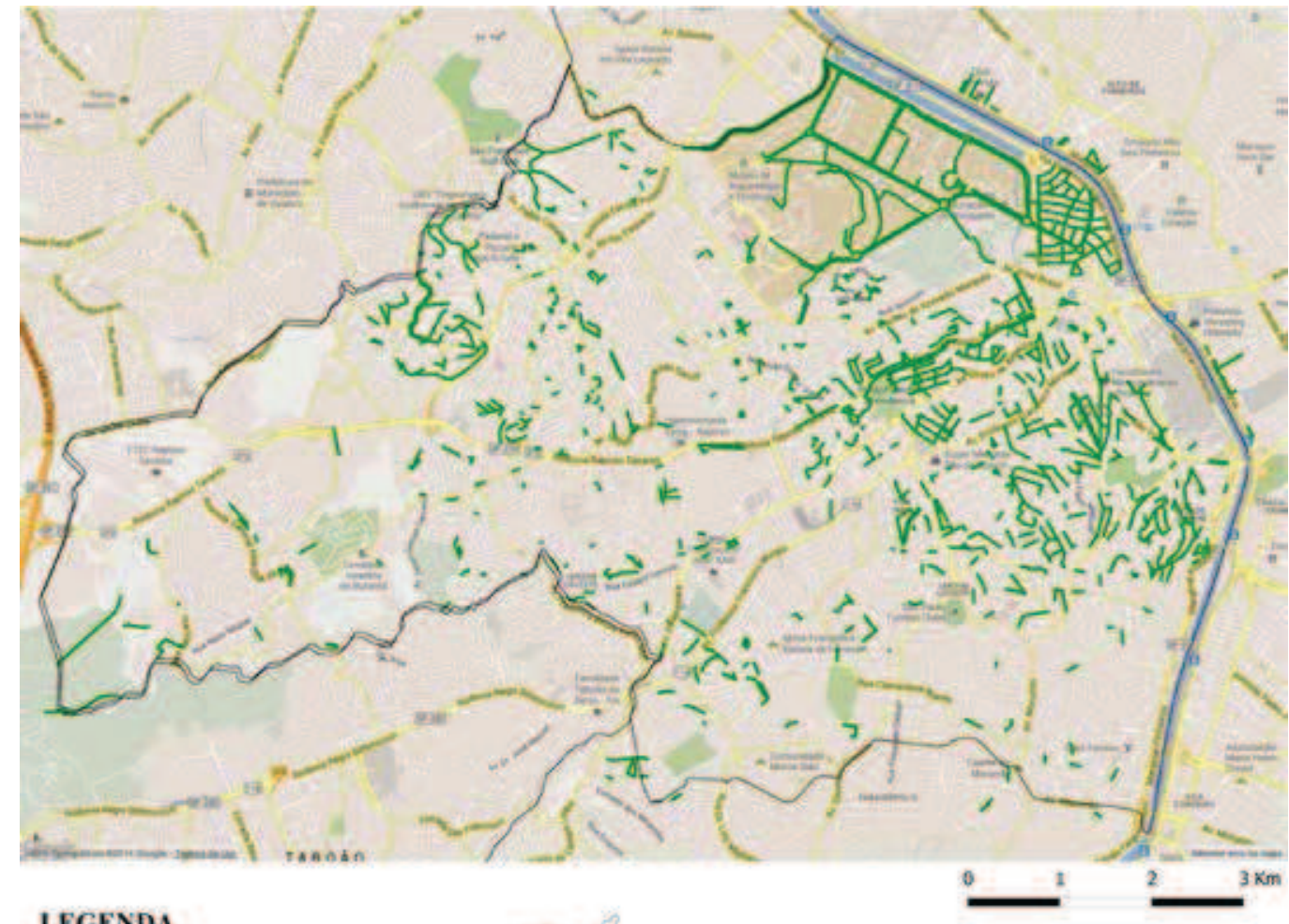

\section{LEGENDA}

EXTENSÄO DE DOSSEL ARBOREO PROJETADO SOBRE O EIXO DA VIA

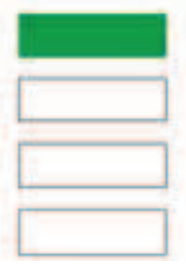

mais de $90 \%$

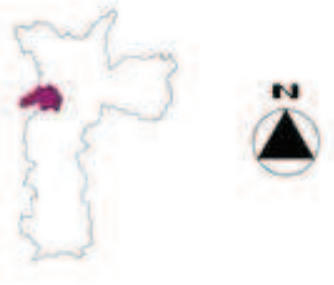

Figura 15 Mapa temático da Subprefeitura Butantã com a seleção das vias muito arborizadas.

Fonte: Produzido por Patrícia Eiko Aguchiku - 2014 
São Paulo - Arborização de Vias Públicas

Subprefeitura Butantã

Mapa temático - método ArbVias

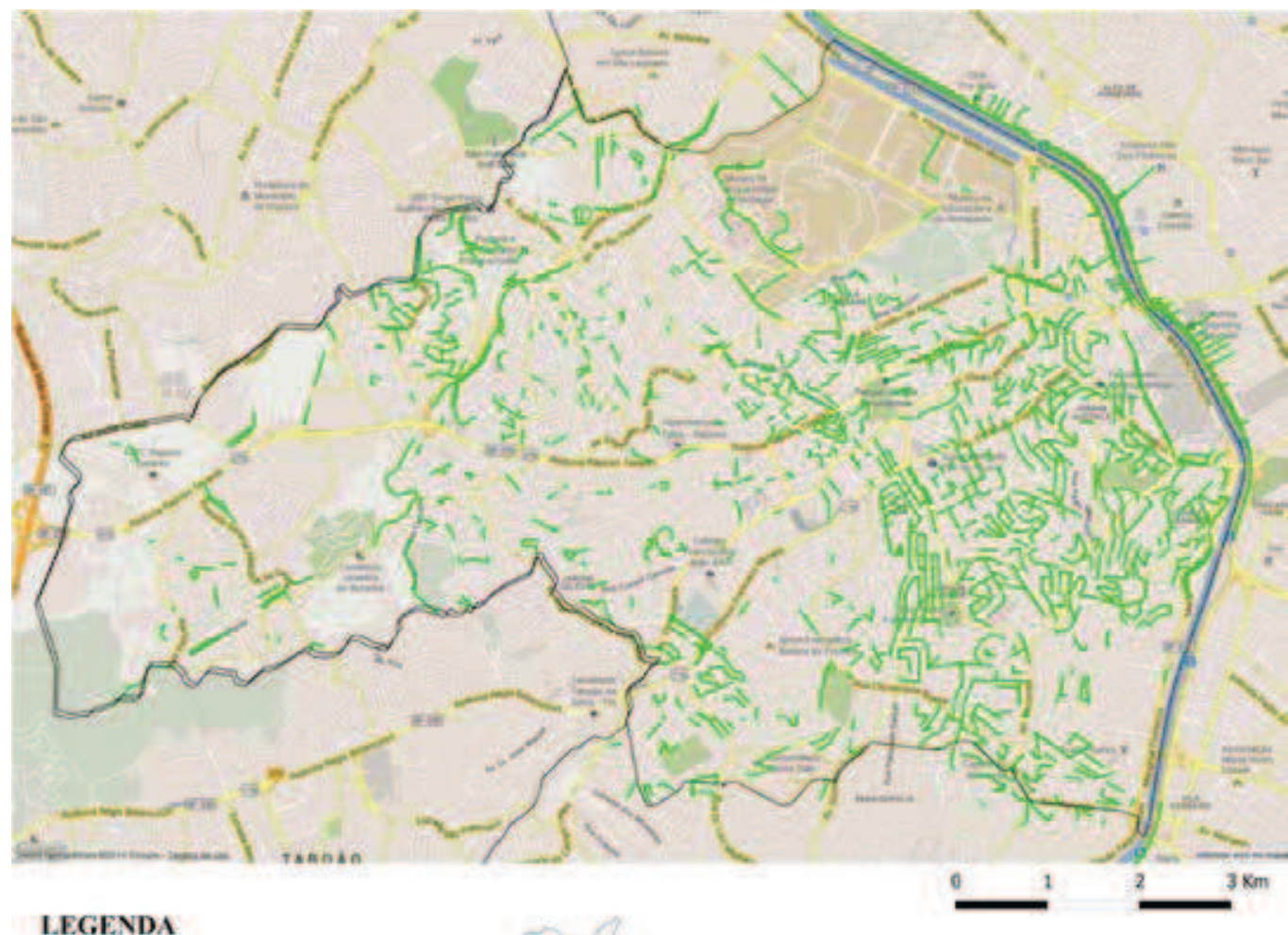

\section{LEGENDA}

EXTENSÄO DE DOSSEL ARBOREO

PROJETADO SOBRE O EIXO DA VIA
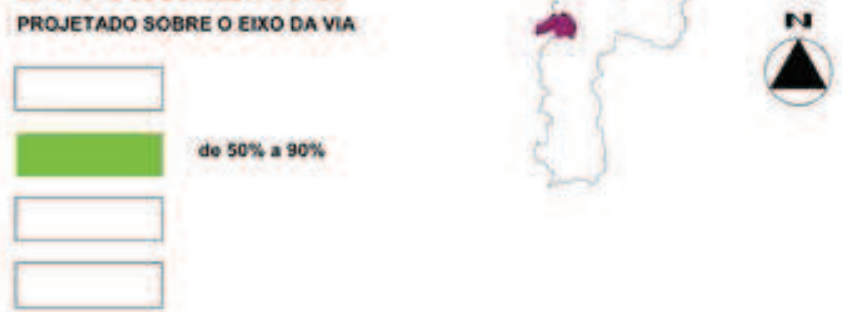

Figura 16 Mapa temático da Subprefeitura Butantã com a seleção das vias medianamente arborizadas.

Fonte: Produzido por Patrícia Eiko Aguchiku - 2014 
São Paulo - Arborização de Vias Públicas

Subprefeitura Butantã

Mapa temático - método ArbVias

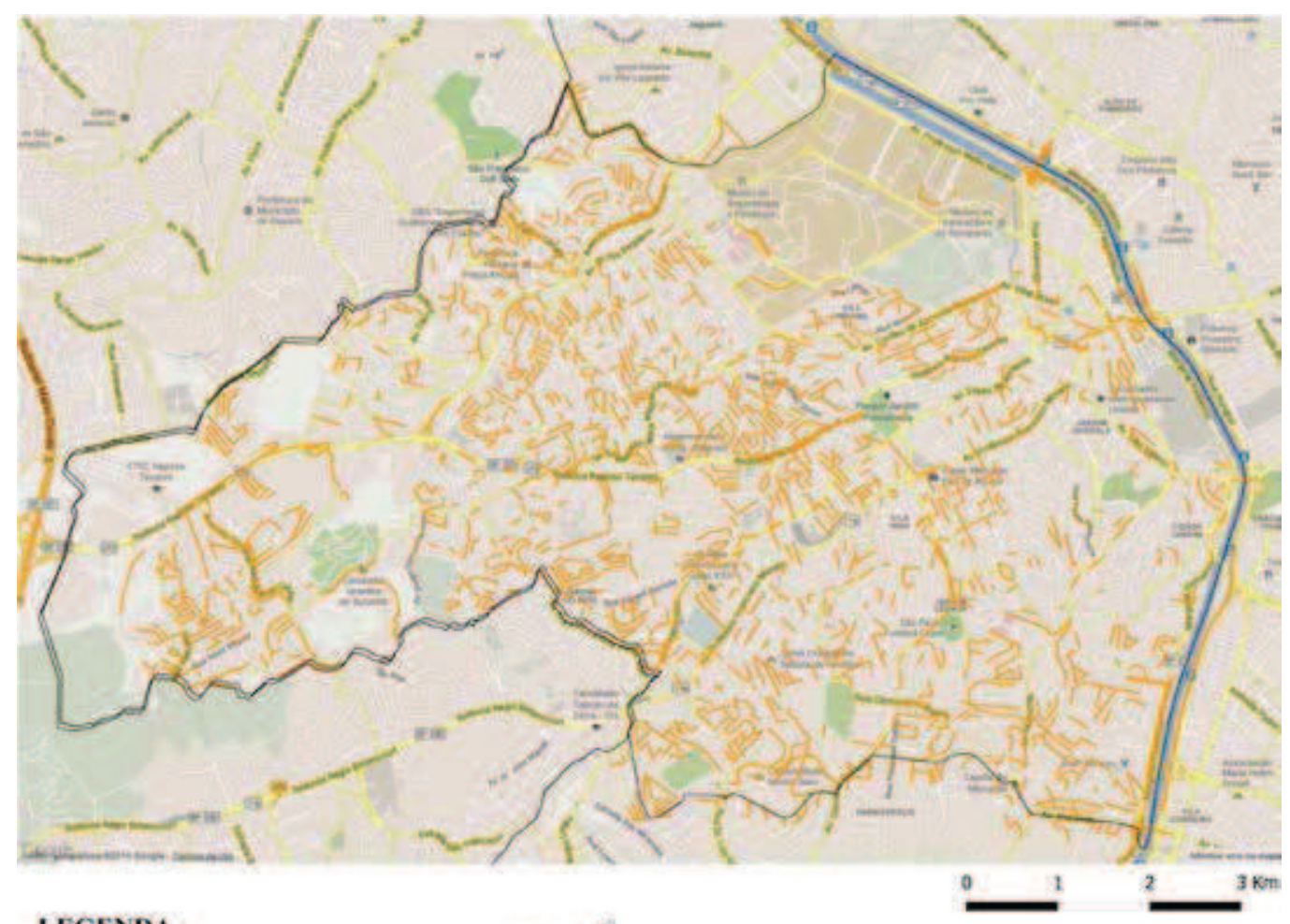

\section{LEGENDA}

EXTENSĀO DE DOSSEL ARBÓREO

PRONETADO SOERE O EIXO OA VIA
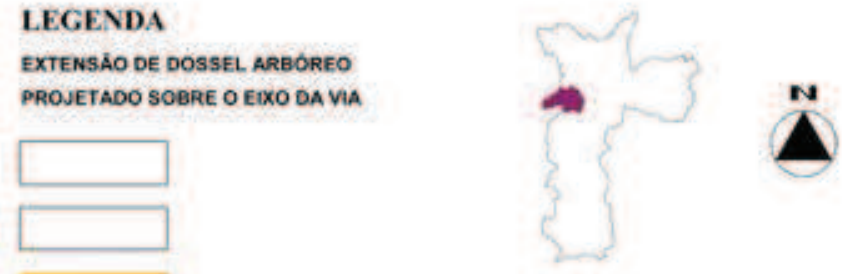

de $10 \%$ a $50 \%$

Figura 17 Mapa temático da Subprefeitura Butantã com a seleção das vias pouco arborizadas. Fonte: Produzido por Patrícia Eiko Aguchiku - 2014 
São Paulo - Arborização de Vias Públicas

Subprefeitura Butantã

Mapa temático - método ArbVias

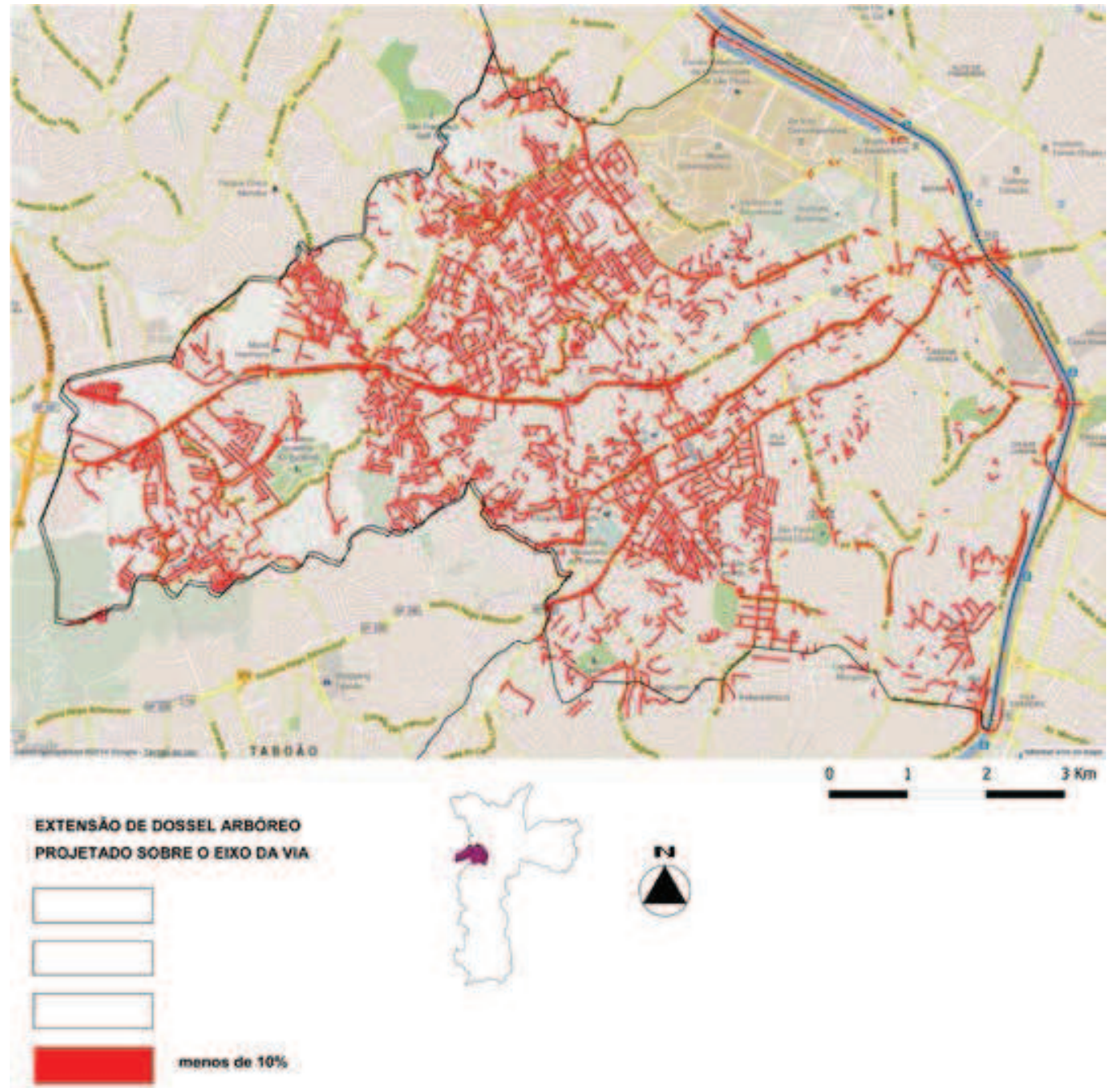

Figura 18 Mapa temático da Subprefeitura Butantã com a seleção das vias sem ou quase sem arborização. Fonte: Produzido por Patrícia Eiko Aguchiku - 2014 


\section{São Paulo - Aspectos da Arborização de Vias Públicas}

Subprefeitura Butantã

\section{Categorização conforme atributos ArbVias}
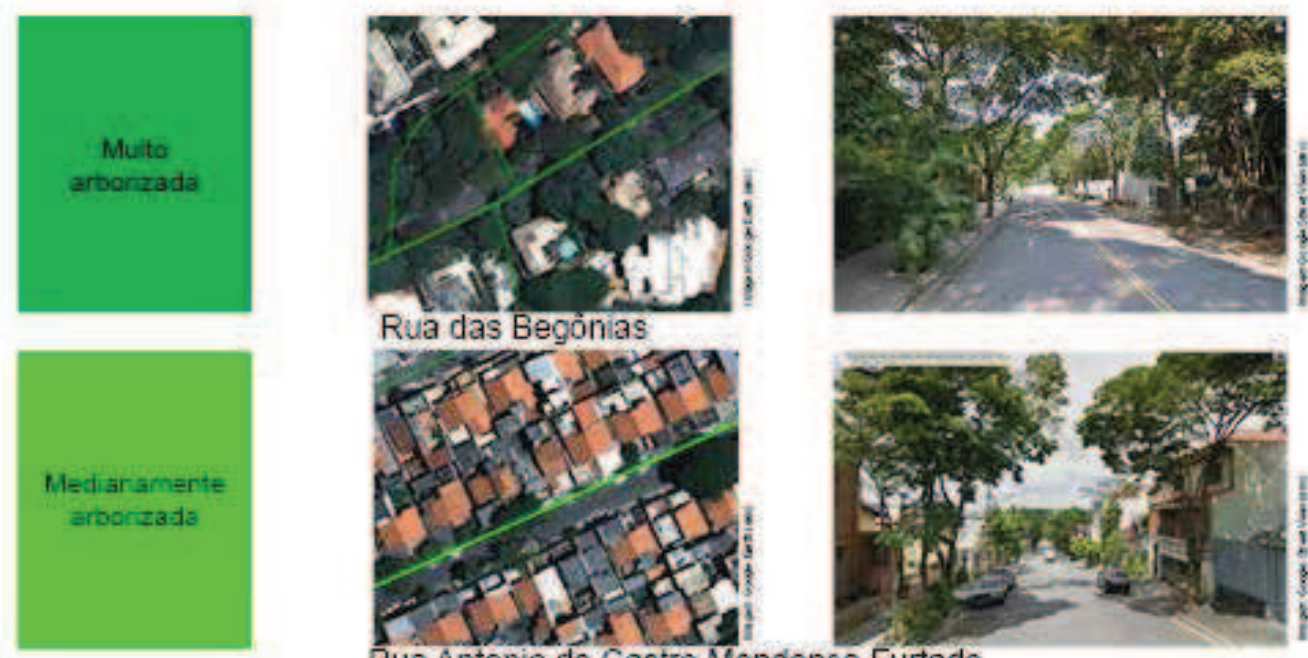

Rua Antonio de Castro Mendonça Furtado
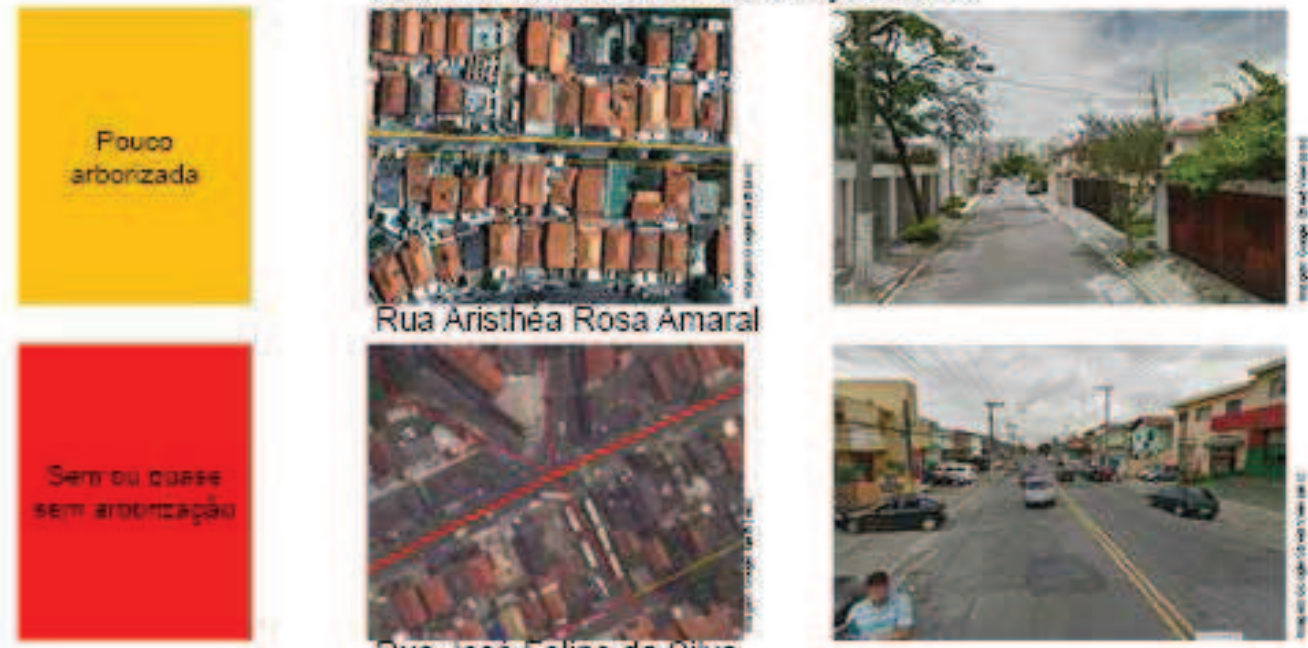

Figura 19 Imagens de vias da Subprefeitura Butantã, com a respectiva foto aérea, avaliadas com cada um dos quatro atributos ArbVias.

Fonte: Google satellite e Google Street View - 2014

\section{LIMITES DO PROCESSO}

No tocante às imagens de satélite disponíveis, mesmo não dispondo de tanta definição quanto nas aerofotos, deve-se considerar que, para o caso de massa de vegetação arbórea não se requer definições tão precisas. Para a aplicação desse método, que resulta na escolha dos atributos muito arborizado (1), medianamente arborizado (2), pouco arborizado (3), sem ou quase sem arborização (4), são suficientes: a definição da área de domínio da via e a identificação das manchas de cobertura do dossel ar- 
bóreo, em que pese a perda de definição na aproximação de imagens de satélite com formato raster (ou bitmap).

Nas confirmações por fotos, normalmente do Street View, oferecido pelo Google Maps, processo que podemos denominar observação horizontal, necessária para esclarecer dúvidas da imagem de satélite (ou foto aérea), o operador deve ter o cuidado para não incorrer na falsa impressão de arborização densa na via, ocasionada pelo efeito cortina de árvores formando painel ao longo da via.

É importante, também, esclarecer que mudas recém-plantadas, arvoretas ou exemplares objeto de topiarias, árvores podadas ou com pouca copa podem não ser detectadas e escapar do processo de análise mesmo dirigido. Algumas pequenas incorreções de análise podem ocorrer, mas, mesmo assim, não invalidam o processo, cujo resultado final converge para a média, que é o que interessa.

\section{CONSIDERAÇÕES FINAIS}

O uso de ferramentas computacionais para geoprocessamento aqui se justifica pela possibilidade da realização de análises complexas. Através de um Sistema Gerenciador de Banco de Dados é possível relacionar bancos de dados georreferenciados para soluções de localização, qualificação e quantificação.

No trabalho ArbVias, é utilizada como modelo a técnica de estimativa georreferenciada de variáveis contínuas ou discretas reveladas em forma de escala padronizada de atributos, cuja hipótese central é a visualização percentual de linhas representativas do dossel da arborização sobre a extensão do eixo da via - as cores da legenda mostram a intensidade de cobertura arbórea ao longo das vias públicas.

Com essa simplificação das variáveis presentes no fenômeno estudado, pela caracterização da área de projeção das copas das árvores ao longo do eixo da via, procurou-se facilitar o conjunto de procedimentos com suporte em mapa vetorizado e foto aérea/imagem de satélite aliado a um modelo inferencial que melhor representasse o cômputo da arborização no sistema viário público urbano.

Esse modelo inferencial tem por objetivo quantificar por padrões percentuais a faixa de dossel, e não por quantidade de árvores, como comumente se admite, em relação ao comprimento da via - o que, a critério da escolha do operador, se traduz pela projeção relativa sobre a "escala gráfica de padronização" (gabarito) em relação à extensão da via. O padrão de representação dos eventos, no caso, linhas ou polilinhas, conforma-se sobre o próprio eixo viário representado pela geometria do shape LSA00713.

Evidentemente, essa premissa tem limitações. As unidades de levantamento são definidas por critérios operacionais de homogeneidade, resultando em indicadores, com alusão a quatro possibilidades: muito, medianamente, pouco ou insignificante.

Com a aplicação do método ArbVias é possível a geração de mapas temáticos para visualização dos quatro indicadores, de maneira conjunta ou isolada. Mesmo sem a

\footnotetext{
13 Fonte: Centro de Estudos da Metrópole (CEM). Bases cartográficas, divisão territorial, logradouros. 
necessidade de grau de precisão elevado, esse recurso pode ser utilizado na tomada de decisões sobre áreas de cidades com carência de arborização no sistema viário.

Caso se verifique a existência de extensas áreas da cidade com vias que não comportam o plantio de árvores de forma expressiva, o método ArbVias pode revelar-se útil instrumento de decisão a ser utilizado em programas de revitalização de vias, calçadas, ou de providências nas áreas públicas ajardinadas e arborizadas, praças ou parques, para melhoria das condições de atendimento da população local em relação a áreas verdes.

Caso se constate regiões com vias identificadas com os atributos ArbVias 2 e 3, pode-se dirigir estudos com programas de plantio para aumento da arborização ou correção estrutural da via. Nos casos de identificação de vias com atributo ArbVias 1, portanto, com consistente arborização junto às vias, pode-se estabelecer para essas áreas programas de gestão com verificação de estado fitossanitário e operações de podas, remoções e reposições planejadas.

O trabalho de mapeamento desenvolvido com tecnologia SIG pode valer-se do uso de atributos convencionados para identificação da sobreposição de cobertura arbórea ao longo do sistema viário urbano, trazendo como benefício uma nova possibilidade de visualização, análise e síntese. Assim, com ênfase na definição de macroidentificações dessa ocupação, é possível comparar outras informações de interesse, desde que disponíveis em banco de dados georreferenciados, como, por exemplo, dados de infraestrutura viária e de uso e ocupação.

Como expectativa de avanço possível, espera-se poder automatizar esse método para sensoriamento remoto, com a utilização de imagens de satélite. Com isso, a produção de mapeamentos da arborização do sistema viário pela adoção do modelo inferencial de níveis de atributos ArbVias poderá ser feita de forma mais ágil, com possível diminuição de custos, podendo ser facilmente estendida para o estudo de qualquer município. Uma das dificuldades a ser solucionada é a adoção de um sistema para a produção automatizada de documentos cartográficos georreferenciados e a identificação dos atributos que caracterizam a distribuição dos eventos. De qualquer forma, tanto assistida como automatizada, parece compensador a aplicação desse método como forma segura e barata de conhecer a arborização do sistema viário de uma cidade. 


\section{REFERÊNCIAS BIBLIOGRÁFICAS}

ANDRADE, Rubens. A construção da paisagem urbana no Brasil: processos e práticas da arborização. In: TERRA, Carlos Gonçalves (Coord.). Arborização: ensaios historiográficos. Rio de Janeiro: EBA/UFRJ, 2004, p. 73-129.

ARQUIVOS SHAPEFILE disponibilizados pelo CESAD-FAU através do Centro de Estudos da Metrópole. Disponível em: <http://www.centrodametropole.org.br/>. Acesso em: 21 fev 2013.

CHEN, P. P. S. The entity-relationship model: towards a unified view of data. ACM Trans. Database System, New York, n. 1, 1976.

GEHL, Jan. Cidades para pessoas. Tradução de Anita Di Marco. São Paulo: Perspectiva, 2013. 272 p.

GEOlnformatics Magazine for Surverying. Mapping \& GIS Professionals, v. 6, 8 dez. 2013, p. 45. Netherlands. Disponível em: <www.geoinformatics.com>. Acesso em: 13 dez 2013.

Imagens de satélite. Disponíveis em: <http://www.apolo 11 .com/satmap2 cidades.php? citynum=26>. Acesso em: 5 jul. 2012.

LISBOA FILHO, J. Estruturação e modelagem de bancos de dados. In: GIS BRASIL, 2001, Curitiba. Apostila do curso apresentado no GIS BRASIL, 2001, Curitiba. Disponível em:

$<$ http://www.ufpa.br/sampaio/curso_de_sbd/semin_bd_para_sig/gisbr2001.pdf > .

MORIN, Edgar. O método 2: a vida da vida. Tradução de Marina Lobo. Porto Alegre: Sulina, 2005. 528 p.

SPIRN, Anne Whiston. O jardim de granito. São Paulo: Edusp, 1995. 249 p.

TERRA, Carlos Gonçalves. Influências externas para a arborização no Brasil. In: TERRA, Carlos Gonçalves (Coord.). Arborização: ensaios historiográficos (Coord.). Rio de Janeiro: EBA/UFRJ, 2004, p. 73-129.

VIGNOLA JR., Roberto. A arborização de vias públicas e a paisagem urbana: caso da cidade de São Paulo. 2005. 155 f. Dissertação (Mestrado em Arquitetura e Urbanismo) - Faculdade de Arquitetura e Urbanismo, Universidade de São Paulo, São Paulo, 2005. 